\title{
Title: Systematic review and meta-analysis of therapeutic alliance, engagement and outcome in psychological therapies for psychosis
}

\author{
Short title: REVIEW OF THERAPEUTIC ALLIANCE IN PSYCHOSIS
}

Bourke, E. ${ }^{* 1,2}$, Barker, C. ${ }^{1}$, and Fornells-Ambrojo, M. ${ }^{1}$

${ }^{1}$ Research Department of Clinical, Educational and Health Psychology, University College London, UK. (Dr. Emilie Bourke's affiliation when review initiated)

${ }^{2}$ DISCOVER Team, Michael Rutter Centre, De Crespigny Park, London, UK. (Dr. Emilie Bourke's current affiliation)

*Corresponding author information: Dr Emilie Bourke, DISCOVER Team, Michael Rutter Centre, De Crespigny Park, Camberwell, London SE5 8AB, United Kingdom (e-mail: emilie.bourke@slam.nhs.uk)

\begin{abstract}
:
Aim: The moderate association between therapeutic alliance (TA) and psychological therapy outcome is wellestablished. Historically, the field has not focused on people with a severe mental illness. This is the first review to conduct a meta-analysis of associations between TA and therapeutic engagement as well as outcome in psychological therapy for psychosis.
\end{abstract}

Eligibility Criteria: Eligible studies conducted a quantitative investigation of the relationship between TA during a psychological therapy and outcome at a subsequent time-point.

Method: A systematic review examined the relationship between TA and engagement as well as outcome measures within psychological therapy for psychosis. Correlational meta-analyses using an aggregate random-effects model were conducted. 
Results: Twenty-four studies were eligible for inclusion $(n=1,656)$ of which 13 were included in the meta-analyses. Client- and therapist-rated TA were associated with engagement in therapy $\left(r_{\text {client }}(c)=0.36, \mathrm{p}=.003 ; r_{\text {therapist }(t)}=0.40\right.$, $\mathrm{p}=.0053)$. TA was also associated with reduction in global $\left(r_{c}=0.29, \mathrm{p}=.0005 ; r_{t}=0.24, \mathrm{p}=.0015\right)$ and psychotic symptoms $\left(r_{c}=0.17, p=.0115 ; r_{t}=0.30, \mathrm{p}=.0003\right)$. The systematic review identified no evidence or limited evidence for a relationship between TA during therapy and depression, substance use, physical health behaviours, global as well as social functioning, overall mental health recovery and self-esteem at follow-up. Although number of studies was small, TA was related to a reduced risk of subsequent hospitalisation in $40 \%$ of analyses (across two studies) and improved cognitive outcome in $50 \%$ of analyses (across three studies).

Conclusions: The observed TA-therapy engagement and TA-outcome associations were broadly consistent with those identified across non-psychotic diagnostic groups. Well-powered studies are needed to investigate the relationship between TA and process as well as outcome in psychological therapy for psychosis specifically.

\section{Keywords:}

ALLIANCE; PSYCHOSES/SEVERE MENTAL ILLNESS; COMMON FACTOR; META-ANALYSIS

\section{Data availability statement:}

The data that support the findings of this study are available in the supplementary materials for this article. Additional review data are available from the corresponding author upon reasonable request.

\section{Acknowledgements:}

The authors wish to thank Dr Hayley Dolan for her thoughtful contributions to research group discussions during the planning phase of the review. 


\section{Practitioner Points}

- This is the first review to conduct a meta-analytic synthesis of the association between therapeutic alliance (TA) and both engagement and change in outcome in psychological therapies for psychosis.

- TA (as rated by therapist and client) was associated with the extent of therapeutic engagement as well as reduction in global mental health symptoms and psychotic symptoms.

- The significant associations between TA and engagement as well as change in outcome identified in the current review are broadly consistent with those observed across nonpsychotic diagnostic groups.

- We consider factors that could impact upon the dynamic and potentially interdependent relationships between TA and therapeutic techniques, including attachment security and severity of paranoid ideation. 


\begin{abstract}
Aim: The moderate association between therapeutic alliance (TA) and psychological therapy outcome is well-established. Historically, the field has not focused on people with a severe mental illness. This is the first review to conduct a meta-analysis of associations between TA and therapeutic engagement as well as outcome in psychological therapy for psychosis.
\end{abstract}

Eligibility Criteria: Eligible studies conducted a quantitative investigation of the relationship between TA during a psychological therapy and outcome at a subsequent time-point.

Method: A systematic review examined the relationship between TA and engagement as well as outcome measures within psychological therapy for psychosis. Correlational metaanalyses using an aggregate random-effects model were conducted.

Results: Twenty-four studies were eligible for inclusion $(n=1,656)$ of which 13 were included in the meta-analyses. Client- and therapist-rated TA were associated with engagement in therapy $\left(r_{\text {client }(c)}=0.36, \mathrm{p}=.003 ; r_{\text {therapist }(t)}=0.40, \mathrm{p}=.0053\right)$. TA was also associated with reduction in global $\left(r_{c}=0.29, \mathrm{p}=.0005 ; r_{t}=0.24, \mathrm{p}=.0015\right)$ and psychotic symptoms $\left(r_{c}=0.17, p=.0115 ; r_{t}=0.30, \mathrm{p}=.0003\right)$. The systematic review identified no evidence or limited evidence for a relationship between TA during therapy and depression, substance use, physical health behaviours, global as well as social functioning, overall mental health recovery and self-esteem at follow-up. Although number of studies was small, TA was related to a reduced risk of subsequent hospitalisation in $40 \%$ of analyses (across two studies) and improved cognitive outcome in 50\% of analyses (across three studies).

Conclusions: The observed TA-therapy engagement and TA-outcome associations were broadly consistent with those identified across non-psychotic diagnostic groups. Wellpowered studies are needed to investigate the relationship between TA and process as well as outcome in psychological therapy for psychosis specifically.

Keywords: Alliance; Psychoses/Severe mental illness; Common factor; Meta-analysis 
Systematic review and meta-analysis of therapeutic alliance, engagement and outcome in psychological therapies for psychosis

When compared against treatment as usual (TAU), theory-informed psychological therapies for psychosis have been shown to map onto specific outcomes (e.g. Cognitive Behaviour Therapy for psychosis [CBTp]) and positive symptoms [Lincoln et al., 2012]; Family Intervention and risk of relapse [Pharoah et al., 2010]; Cognitive Remediation Therapy [CRT] and cognitive functioning [McGurk et al., 2007]). However, meta-analytic evidence for this specific match between therapy and outcome is more variable when active comparison groups are included. For example, CBTp has been found to outperform TAU but not other psychological interventions in its impact on delusions (Mehl et al., 2015), whereas CRT has been found to have a significant effect on global cognitive outcome regardless of the type of comparison group (Wykes et al., 2011). Psychological therapies can also have a broader beneficial impact beyond their "primary target". For instance, although CRT and Social Skills Training primarily target cognitive difficulties and impaired social functioning respectively, they have also been found to reduce negative symptoms (Cella et al., 2017; Turner et al., 2017).

One strong interpretation of such evidence is that it lends support to the longstanding "Dodo Bird"1 argument for equivalence in outcome across psychological treatments, independent of techniques that are specific to a certain therapy (or "specific factors") (Rosenzweig, 1936; Wampold, 2001). A logical alternative account is that different therapeutic modalities may achieve these similar outcomes but via different processes (i.e. maintaining an important role for specific factors; DeRubeis et al., 2005). In the context of

\footnotetext{
${ }^{1}$ Reference first made by Rosenzweig (1936) and derived from the Caucus-race in Lewis Carroll's 'Alice and Wonderland' ("At last the Dodo bird said, 'Everybody has won and all must have prizes'"). Rosenzweig used this metaphor to assert the general equivalence of benefits across psychotherapeutic modalities; a perspective which has come to be called the "Dodo Bird Effect".
} 
this debate, it is equally valuable to understand the contribution of "non-specific factors". These are aspects of therapy that are considered common across the diverse range of contemporary modalities (Meichenbaum \& Lilienfeld, 2018), such as perceived trustworthiness of the therapist. It has been suggested that non-specific factors can be directly beneficial for treatment outcome in themselves (Huibers \& Cuijpers, 2015; Lambert, 2013) and, of these, the therapeutic alliance (TA) is perhaps the most widely acknowledged (Wampold, 2001; DeRubeis et al., 2005).

\section{Why Investigate the Therapeutic Alliance in Psychosis?}

The TA can be defined as the collaborative and affective bond between therapist and client (Martin et al., 2000). The TA construct was explored originally within the field of psychodynamic psychotherapy by Freud (1913) who ventured that the patient-therapist transference is made up of a range of elements; some of which drive the patient to resist the therapy process, while others drive their continued engagement. Thus, he framed the TA as one of the latter "effective" aspects of the transference (Freud, 1913; Friedman, 1969). Within Rogers' (1957) person-centred approach, the TA also plays an essential role in the client's experience of positive therapeutic change. Rogers ventures that the therapist must: experience "unconditional positive regard" towards their client, take an empathic understanding of their internal world and successfully communicate this stance to the client over the course of their contact. Bordin (1979) argued for the pantheoretical nature of TA ${ }^{2}$ and specified three core dimensions: (1) collaboration on relevant tasks, (2) agreement on valued goals, and (3) the trusting, human bond between client and therapist. Although these dimensions take on a different quality in different modalities, Bordin (1980) proposed that they are essential to the success of therapeutic work.

2 "Therapeutic alliance" is used here for consistency, although Bordin used the term "working alliance". 
Table 1 gives an overview of how the TA is conceptualised in current psychological therapies for psychosis. Although each acknowledges the importance of the TA, they differ in terms of its hypothesised role in the efficacy of the therapy. For example, it could be that service users with a generalized capacity for forging strong interpersonal relationships are most able to develop and benefit from the TA (Zilcha-Mano, 2017). By comparison, therapies such as Motivational Interviewing conceptualise the therapist's offer of unconditional positive regard and acceptance as directly beneficial in their own right.

Service users with psychosis value collaborative therapeutic relationships (Wood et al., 2015) and attribute the success of cognitive therapy to therapist empathy and trustworthiness in particular (Lawlor et al., 2017). However, poor alliance (Berry et al., 2018) and poor engagement with services (Blackburn et al., 2010; Berry et al., 2007 ${ }^{\text {b }}$ ) are common. This is perhaps unsurprising given the high prevalence of insecure attachment among this clinical group (Berry et al., 2007ª Carr et al., 2017; Gumley et al., 2014). According to attachment theory, the quality of our bonds with early caregivers shape how we navigate our interpersonal relationships and emotional experience in the here-and-now (e.g. Bowlby, 1988). Thus, although distinct concepts, there is a plausible connection between a person's attachment style and their ability to forge a TA with a new therapist. Indeed, increasingly, contemporary psychological therapies are targeting relational and interpersonal themes directly in psychosis (e.g. AVATAR Therapy [Craig et al., 2018]; Relating Therapy [Hayward et al., 2017]).

\section{[TABLE 1 HERE]}

\section{Relationship between Therapeutic Alliance and Outcome: Existing Reviews}

Reviews of the link between TA and psychotherapy outcome have identified a moderate association between higher quality TA and positive therapy outcome (Flückiger et al., $2018[r$ $=.29]$; Horvath $\&$ Symonds, $1991[r=.26]$; Martin et al., $2000[r=.22])$. More recently, 
Shattock et al.'s (2018) qualitative synthesis established that the TA can be established early on in psychological therapy for non-affective psychosis and is maintained or even improves over time (their paper reports that the weighted average TA ratings observed in this population were comparable to those of other client groups). This existing review found that, among the eight included studies that examined the TA-outcome relationship (published up to April 2015), there was support for a predictive relationship between TA and overall psychotic symptoms as well as promising links to rehospitalisation, self-esteem and medication compliance.

\section{The Present Study}

This paper aims to report a systematic review of the literature that investigates the relationship between TA and therapy process as well as outcome in psychological therapies for psychosis. A further objective was to conduct the first meta-analysis of the association between TA and measures of recovery. As informed by the existing evidence base, we hypothesised tentatively that the relationship between TA and outcome in psychosis would be comparable to that observed in other diagnostic groups and in non-affective psychosis specifically (Shattock et al., 2018). As this review was conducted originally as part of the first author's Doctoral thesis, no protocol was published in advance.

\section{Methods}

\section{Eligibility Criteria}

Inclusion criteria for studies were as follows: (i) service users with a diagnosis of either affective or non-affective psychosis as the study participants; (ii) a psychological therapy of any modality and format; (iii) a quantitative measure of TA, whether client, clinician or observer-rated; (iv) a quantitative measure of therapy process or outcome; (v) assessment of TA during therapy as well as outcome at one "baseline" time-point (T1) and again at a later time-point (T2). It was required that T2 was after assessment of alliance but this could have 
been during therapy, at the end of therapy or at a pre-specified follow-up time post-therapy completion; (vi) an article/academic conference abstract published in a peer-reviewed journal or an unpublished thesis project. Originally, there was a further inclusion criterion regarding participant age (i.e. 16 years and above), however this was removed as the systematic search identified no studies that met all other eligibility criteria and included a child sample. Studies were excluded if they used medication adherence as their only outcome measure.

\section{Search Strategy}

PubMed, PsycInfo and EMBASE were searched across the time-span from each database's start-date to $31^{\text {st }}$ July 2020 using the terms outlined in Supplementary Material A. These terms were also applied in a search of Google Scholar. A three-part hand search was conducted: (1) using the reference lists of papers known to be eligible for inclusion and (2) replicating the search of journal titles screened by Martin and colleagues (2000) in their meta-analysis of the relationship between TA and outcome across diagnostic categories for the period January 2016 up to the end of July 2020. (3) This hand search was extended to the following journals to reflect the specific research questions of the current review (same timeframe as in step (2) above): Psychosis: Psychological, Social and Integrative Approaches, Schizophrenia Research, Schizophrenia Bulletin, Cognitive and Behavioural Psychotherapy and Journal of Clinical Psychology.

Study title and abstract were screened for eligibility followed by full texts. It was decided in advance that, if papers were found to be eligible after the full-text screen but did not report the specific analyses of interest, the corresponding author would be contacted to request further information (giving a 1-month deadline for response). Each step of the search protocol was carried out by first author (Doctoral student with a ScM qualification ${ }^{3}$ ). She

\footnotetext{
${ }^{3}$ At the time when the original literature search was conducted, now DClinPsy.
} 
discussed papers with the other two authors if their eligibility was unclear or if she planned to contact the corresponding author for additional information.

\section{Assessment of Methodological Quality}

The National Institutes of Health (NIH; 2014) quality assessment tool for pre-post studies with no control group was adapted for this review (see Supplementary Material B). This tool includes assessment criteria ranging from the study sample and therapy fidelity monitoring, to the psychometric properties of the outcome measures and the quality with which statistical analyses are reported. We chose to expand the item about statistical reporting to include whether each paper reported both significant and non-significant findings. Such complete reporting was crucial in light of the planned meta-analytic approach. In a further adaptation, the binary 'yes'-'no' rating system was replaced with a 3-point scale to enable more nuanced quality assessment.

\section{Assessment of Association between Therapeutic Alliance and Outcome}

Effect sizes for the meta-analyses of association between TA and outcome were extracted between two time points. The earliest available alliance measure was extracted, along with the outcome variable from the $\mathrm{T} 1$ and $\mathrm{T} 2$ waves of data collection (where $\mathrm{T} 1$ represents the baseline assessment). These were used to calculate the raw difference score for the outcome measure of interest if this had not already been reported in the original study. If there were multiple repeated waves of outcome assessment, the outcome from the final timepoint that was included in the paper's analysis was extracted and applied as the T2. Statistical analyses were carried out with the R software (Version 3.4.2), using the metafor package (Viechtbauer, 2010). The meta-analytic model weighted the effect size from each paper based on sample size. Meta-analysis effect sizes were calculated using Fisher's $z$ correlation coefficient. A random effects model was applied as this approach allows for the fact that 
effect sizes within a meta-analysis can vary due to random error as well as other differences arising when studies are conducted independently of one another.

The $Q$-statistic and $I^{2}$ were used as measures of heterogeneity between studies (Siddaway et al., 2019). The power of the $Q$-statistic has been found to be low where a metaanalysis includes a small number of studies. $I^{2}$ was applied here as a supplementary measure which does not depend on the number of studies in a meta-analysis (Higgins et al., 2003). $I^{2}$ was interpreted using Higgins and colleagues' guidance thresholds ${ }^{4}$.

Two methods were used to estimate the risk of publication bias: (1) funnel plot inspection and (2) "fail-safe $N$ " calculation. A funnel plot visually represents the sample size of each study against the size of the effect they report. Although often not inspected where the number of studies is small, funnel plots were used here as one way to detect publication bias, especially if the scatter of small studies were to indicate that a positive effect was reported more often than a negative effect (Lee \& Hotopf, 2012). Orwin's (1983) formula for calculating fail-safe $N$ was also applied. This calculation allows us to estimate how many additional studies with a null result would be needed within each meta-analysis before the observed association between TA and therapy process/change in outcome would become non-significant (i.e. bringing the $p$ value above .05). This method is debated, for example, given its reliance on the arbitrary nature of $p$ value thresholds (e.g. Higgins \& Green, 2011). Thus, fail-safe $N$ together with funnel plot inspection were included to explore the degree of potential publication bias and interpreted cautiously.

\section{Results}

The PRISMA diagram (Figure 1) details the break-down of papers identified. After excluding duplicate records, the first pass of screening titles and abstracts was conducted for

\footnotetext{
${ }^{4}$ Higgins et al.'s (2003) tentative labels for evaluating the value of $I^{2}$ are as follows: "low" (25\%), "moderate" (50\%), "high" (75\%).
} 
3,138 papers using the inclusion and exclusion criteria. Figure 1 details the rationale for inclusion/exclusion of papers at each stage of the screening process.

\section{[FIGURE 1 HERE]}

\section{Included Studies}

The final 24 papers were published between 1990-2019 and represent Western samples (see Table 2). They represent data collected from 1,656 participants with a psychotic diagnosis. The sample was predominantly male (across all studies, proportion of male participants ranged from $42.9 \%-90.4 \%$ ) and the average age was 33.6 years old ${ }^{5}$. Some studies recruited participants with non-affective psychosis only (e.g. Goldsmith et al., 2015), while others focused on those who were living with a dual diagnosis (i.e. psychosis and a substance use disorder; Berry et al., 2015; Berry et al., 2016).

Psychological therapies featured across the final papers represented one-to-one $(k=18)$, group $(k=5)$ and combined individual and group $(k=1)$ formats. Therapeutic modalities were diverse: CBTp (in-person or telephone-delivered; $k=7$ ), CBT or another psychological therapy (i.e. participants were either allocated to CBT or skills training for symptom management, Supportive Therapy or Supportive Counselling and papers combined both of these treatment arms from an existing study in their analyses; $k=3$ ), Cognitive Remediation Therapy $(k=3)$, individual psychotherapy $(k=2)$, Motivational Interviewing (MI) plus CBT $(k=2)$, Acceptance and Commitment Therapy $(k=1)$, CBT for weight loss $(k=1)$, Compensatory Cognitive Training $(k=1)$, Treatment Adherence Therapy (combination of behavioural and MI techniques; $k=1)$, individual resiliency training $(k=1)$, Family Intervention $(k=1)$ and a "Healthy Lifestyles Intervention" (CBT and contingent reinforcement techniques; $k=1$ ).

\footnotetext{
${ }^{5}$ Excludes Hammond et al. (2004), Hassan et al. (2014), Jones et al. (2017) \& Svensson and Hansson's (1999) samples, as average age was not available.
} 
Final T2 for data collection was conducted across the following time points: after therapy $(k=8)$, at the end of therapy $(k=9)$ or while therapy was ongoing $(k=2)$. In a further five papers, there was variability according to whether T2 was conducted during or at the end of therapy as access to the psychological therapy of interest was either available for the whole study period or for the course of an inpatient admission. Overall, the range in timing of T2 was 9 weeks-24 months after baseline assessment.

\section{[TABLE 2 HERE]}

\section{Assessment of Methodological Quality}

Individual ratings of each paper's methodological quality according to the adapted NIH assessment tool are detailed in Supplementary Material C. Fourteen papers delivered a manualized therapy and ten reported monitoring treatment fidelity rigorously. A degree of blinding was incorporated into the outcome assessment of five papers. For the remaining studies, assessments at T2 could have been biased by awareness of the quality of the clienttherapist relationship during therapy. Most papers fulfilled the criterion of reporting change in the outcome of interest (20/24; Constantino et al., 2017; NIH, 2014), rather than the raw $\mathrm{T} 2$ score (or were able to share these data on request).

\section{Quality of Measures}

Assessment of Therapeutic Alliance. Nine different measures of TA were used. The majority were well-validated and received the maximum quality rating. The Working Alliance Inventory (WAI; Horvath \& Greenberg, 1989) was the most commonly used. Most papers assessed the client and/or therapist view of TA. Timing of assessment varied between studies; common lengths were 1-3 months after the start of therapy with a range of 0- 6 months. 
Assessment of Therapy Process \& Outcome. Over ten different indices of therapy process or therapeutic outcome were applied ${ }^{6}$. Only a small minority of outcome measures were evaluated below the highest methodological quality rating. Across the papers that were included in the meta-analyses, one study was assigned less than a "high" or "acceptable" rating for their outcome measure because therapists conducted a subjective evaluation of global symptom change (Mulligan et al., 2014).

\section{Systematic Review \& Meta-Analyses}

Twenty-four papers were synthesized qualitatively in the systematic review. Table 3 presents a visual summary of the relationship between TA and engagement (as a therapy process variable) as well as TA and a range of outcome domains (global psychiatric symptoms, psychotic symptoms, depression, insight, self-esteem, mental health recovery, substance use, global functioning, social functioning, cognition physical health and (re)hospitalisation) (see Supplementary Material D for a tabular summary of the effect of the TA on each study's primary outcome only).

The papers applied a range of outcome measures and statistical analyses to examine the role of the TA. Thirteen of these were consistent in that they all examined the correlation between TA during therapy and (1) therapeutic engagement, (2) change in global symptoms or (3) change in psychotic symptoms. Therefore, these papers were synthesised in correlational meta-analyses. For the symptomatology outcomes, the difference between $\mathrm{T} 1$ and T2 outcome scores was applied (rather than the raw T2 score alone) because this approach increases the ability to identify any TA-to-outcome direction of effect (Constantino et al., 2017; NIH, 2014).

Of the papers included in the meta-analysis stage, the number of therapy sessions ranged from 8-40 and spanned 2 months- 2 years. Six of the papers delivered CBTp

\footnotetext{
${ }^{6}$ For clarity, only those outcome measures $(n=13)$ that were used in at least two papers are reported.
} 
(independently or combined with MI techniques) in a one-to-one, group or telephonedelivered format. The remaining psychological therapies were Cognitive Remediation Therapy, Acceptance and Commitment Therapy, Treatment Adherence Therapy, individual psychotherapy and a "Healthy Lifestyles Intervention" (CBT and contingent reinforcement techniques). The final T2 for data collection was conducted at the following stages: while therapy was ongoing $(k=1)$, at the end of therapy $(k=7)$, after therapy $(k=4)$ and either at the end of/after therapy, depending on client choice in psychotherapy $(k=1$; Frank \& Gunderson, 1990). Overall, the range in timing of T2 was 9 weeks-24 months after baseline assessment (respectively, after Session 9 of therapy [Dunn et al., 2006] and at the end of the study period [Frank \& Gunderson, 1990]).

\section{[TABLE 3 HERE]}

\section{Therapeutic Alliance \& Engagement in Therapy}

Half of the analyses that examined the association between TA and engagement in therapy identified a significant association (7/14 analyses in nine studies). These studies operationalised engagement as session attendance, session participation or time spent practicing therapy tasks.

The aggregate random effects estimate for client-rated alliance and engagement throughout the course of psychological therapy was $r=0.36(k=5 ; 95 \% \mathrm{CI}=0.13-0.60 ; \mathrm{Z}=$ $\left.2.99 ; \mathrm{p}=.003 ; \mathrm{R}^{2}=0.13\right)$. This overall effect size represents the association between alliance and engagement (i.e. treatment retention, number of therapy sessions attended/missed or time spent completing Cognitive Remediation Training exercises). Clients who reported a stronger alliance during psychological therapy showed higher levels of engagement (see Figure 2a) for forest plot). The significant $Q$ value of $14.06(p=.007)$ suggests that the heterogeneity between effect sizes was greater than would expected based on sampling error and an $I^{2}$ of $68.67 \%$ indicated a moderate-to-high level of variance. The asymmetry of the funnel plot 
may reflect an increased risk of publication bias. The fail-safe $N$ calculation could offer further indication of this risk. Approximately three additional studies with a null finding would be needed to render the overall observed association non-significant (see Supplementary Material E for funnel plots and fail-safe $N$ calculations for all meta-analyses).

The aggregate random effects estimate for therapist-rated alliance and engagement throughout the course of psychological therapy was $r=0.40(k=4 ; 95 \% \mathrm{CI}=0.12-0.68 ; \mathrm{Z}=$ $\left.2.79 ; \mathrm{p}=.0053 ; \mathrm{R}^{2}=0.16\right)$. The stronger the alliance reported by therapists, the higher the level of client engagement (see Figure 2b) for forest plot). This overall effect size represents the association between therapist-rated alliance and engagement, where engagement was operationalised as number of sessions attended/missed or treatment retention. However, the asymmetry of the funnel plot and fail-safe $N$ calculation may highlight a risk of publication bias. As with the meta-analysis for client-rated TA and engagement, the addition of just under three hypothetical null studies would bring the $p$ value of the observed association above the .05 threshold for significance.

[FIGURE 2 HERE]

The significant $\mathrm{Q}$ value of $14.57(\mathrm{p}=.002)$ suggests that the heterogeneity between effect sizes was greater than would expected based on sampling error. In light of this high level of heterogeneity $\left(I^{2}=78.98 \%\right)$, a sensitivity analysis was conducted (Higgins \& Green, 2011). One potential basis for the observed heterogeneity could be variation in the focus of therapy. Andrews et al.'s (2016) study had the second largest sample of the four studies and found that the association between therapist-rated alliance and engagement was nonsignificant. This study was unique in focusing on physical as well as mental health difficulties in their "Healthy Lifestyles Intervention" for service users who were diagnosed with psychosis and identified as a smoker. A second contributing factor may have been that this paper analysed data about the quality of the TA after just the first session, whereas the 
remaining papers did so after Session 3,1 month of therapy and 6 months of therapy (Mulligan et al., 2014; Berry et al., 2016; Frank \& Gunderson, 1990, respectively). When the meta-analysis was repeated dropping the Andrews et al. paper, the significant association was maintained; the stronger the therapist-rated alliance, the higher the level of client engagement $(r=0.52(k=3 ; 95 \% \mathrm{CI}=0.35-0.68 ; \mathrm{Z}=6.17 ; \mathrm{p}=<.001))$. Notably, the $\mathrm{Q}$ value of 1.90 was non-significant $(\mathrm{p}=0.39)$ and the $I^{2}$ reduced to $16.16 \%$, indicating a low level of heterogeneity (the forest plot and funnel plot for this sensitivity analysis are reported in Supplementary Material F). In sum, the observed association between therapist-rated alliance and engagement remained significant after excluding a study that was identified as a potential source of heterogeneity.

\section{Therapeutic Alliance \& Symptomatology Outcome: Global \& Psychotic Symptoms}

Global Psychiatric Symptoms. The systematic review identified that just under one third of relevant analyses (4/13 in eight studies) reported a relationship between TA and global symptomatic recovery at T2. However, the meta-analyses for client- as well as therapist-rated TA showed a significant and consistent overall association. The aggregate random effects estimate for client-rated alliance and change in global symptoms at T2 was $r$ $=0.29\left(k=5 ; 95 \% \mathrm{CI}=0.13-0.45 ; \mathrm{Z}=3.50 ; \mathrm{p}=.0005 ; \mathrm{R}^{2}=0.08\right)($ see Figure $3 \mathrm{a})$ for forest plot). This overall effect size represents the association between alliance and change in global symptoms as rated on the Brief Psychiatric Rating Scale (BRPS-24; Ventura et al., 2000), the Target Complaints Scale (Battle et al., 1966) or therapist-rated evaluation of change. Clients who reported a stronger alliance during psychological therapy showed greater improvement in global symptoms at T2. A non-significant $\mathrm{Q}$ value of $2.83(p=.59)$ indicated that the heterogeneity between effect sizes was not greater than what would be expected based on sampling error. As $I^{2}$ was $0 \%$, we can infer that the observed variance was not due to between-study variance. 
Six papers examined therapist-rated alliance in relation to change in global symptoms. The aggregate random effects estimate was $r=0.24(k=6 ; 95 \% \mathrm{CI}=0.09-0.39 ; \mathrm{Z}=3.17 ; \mathrm{p}$ $\left.=.0015 ; \mathrm{R}^{2}=0.06\right)$, suggesting that higher quality therapist-rated alliance was associated with greater improvement in client symptoms at T2 (see Figure 3b) for forest plot). This overall effect size represents the association between alliance and change in global symptoms with the latter operationalised using the BPRS, Target Complaints Scale, therapist-rated evaluation of change or Frank and Gunderson's (1990) combination of validated scales derived through factor- and cluster-analysis. Heterogeneity testing generated a nonsignificant Q value of $4.91(\mathrm{p}=.43)$ and $I^{2}$ was $10.42 \%$, indicating a low level of variance.

[FIGURE 3 HERE]

Psychotic Symptoms. In the systematic review, just under half of analyses (6/13 in nine papers) reported a relationship between TA and improvement in psychotic symptoms at a T2 as seen in Table 3. In a unique study, Goldsmith et al. (2015) found that higher attendance predicted an improvement in outcome only where there was a strong TA. Where alliance was poor, a higher dose of therapy had a reverse, detrimental impact.

Five papers were suitable for inclusion in the meta-analysis stage as they all examined the association between client-rated TA and change in psychotic symptoms. Four of the papers used subscale(s) of the PANSS (Kay et al., 1987) while Lecomte et al. (2015) reported their findings from the PSYRATS (Haddock et al., 1999) separately for delusions and hallucinations. The meta-analysis was trialled using the delusions measure only, the hallucinations measure only and with this paper excluded. As the results were highly similar, the PSYRATS delusions measure was applied because it represented the largest sample size $\left(r=0.17 ; k=5 ; 95 \% \mathrm{CI}=0.04-0.30 ; \mathrm{Z}=2.53 ; p=.0115 ; \mathrm{R}^{2}=0.03\right)$. The $\mathrm{Q}$ value $(0.57, p=$ .97) was non-significant indicating that the heterogeneity between effect sizes was not greater than what would be expected due to sampling error. $I^{2}$ was $0 \%$, indicating that the observed 
variance was not due to variance between studies. As shown in Figure 3c), the significant association from this meta-analysis suggests that higher quality client-rated alliance was associated with greater improvement in psychotic symptoms at $\mathrm{T} 2$.

Three of the final papers tested the association between therapist-rated TA and change in positive psychotic symptoms (specific outcome measures were as above or Frank \& Gunderson's combination of validated scales). Higher quality therapist-rated alliance was associated with greater improvement in psychotic symptoms at $\mathrm{T} 2(r=0.30 ; k=3 ; 95 \% \mathrm{CI}=$ 0.14-0.46; $Z=3.59 ; p=.0003 ; R^{2}=0.09$ ) (see Figure 3d) for forest plot). The Q-statistic was non-significant $(0.28, p=.87)$ which suggests that heterogeneity between effect sizes was not greater than what would be expected when sampling error is considered. $I^{2}$ was $0 \%$ indicating that the observed variance was not due to variance between studies. Based on the fail-safe $N$ calculation, just one additional study reporting a null finding would render this overall association non-significant ${ }^{7}$. Whilst this could be interpreted as indicative of publication bias, it is important to note that the number of included studies has a direct bearing on Orwin's (1983) formula (see Supplementary Material E). Thus, with an $N_{0}$ of just three studies, we cannot draw accurate conclusions regarding the degree to which the "file-drawer phenomenon" (Rosenthal, 1979) has impacted the observed association.

\section{Potential Moderating Factors for Associations with Engagement and}

\section{Symptomatology.}

Therapy Duration and Timing of T2 Outcome Assessment. The three papers that were included in the meta-analyses and reported a significant effect of TA as rated by either client or therapist on change in psychotic symptoms (Berry et al., 2015; Frank \& Gunderson, 1990; Staring et al., 2011) examined substantially longer courses of therapy (6 months- 2 years) with later T2 timings for outcome assessment (1-2 years post-baseline), relative to those that did

\footnotetext{
${ }^{7}$ With Cohen's convention of .5 for a "medium"-sized effect applied in the calculation.
} 
not (Dunn et al., 2006; Huddy et al., 2012; Lecomte et al., 2015; White et al., 2011). For example, Berry et al. (2016) reported that TA was not a meaningful predictor at the end of a brief course of therapy (lasting 4.5 months), but it became related to reduced psychotic symptoms at 9- and 18-month follow-up.

Therapeutic Modality. We aimed to explore the potential role of therapeutic modality in the meta-analyses through examination of study characteristics in Table 3 together with the forest plots for the association between TA and engagement as well as change in symptomatology over time (Figures 2 and 3 ). The below observations are organised by dependent variable: therapeutic engagement, change in global symptoms and change in psychotic symptoms.

Engagement. Across raters, engagement in therapy was associated with TA in individual psychotherapy (Frank \& Gunderson, 1990) and Cognitive Remediation Therapy (Hargreaves et al., 2018) studies, but not in the Healthy Lifestyles Intervention (Andrew et al., 2016). The remaining studies (CBTp, Mulligan et al., 2014; CBTp plus MI, Berry et al., 2016; CBT or group Supportive Therapy, Johnson et al., 2008) lacked consistency in results across raters.

Global symptoms. TA was associated with change in global symptoms in individual psychotherapy (Frank \& Gunderson, 1990) but not in CBTp studies (Lecomte et al., 2015; Mulligan et al., 2014). The remaining studies showed an inconsistent picture depending on whether TA was client- or therapist-rated (Health Lifestyles Intervention, Andrews et al., 2016; Cognitive Remediation, Huddy et al., 2012; CBTp or Skills Training, Lecomte et al. 2012).

Psychotic symptoms. Similarly, TA was associated with change in psychotic symptoms in individual psychotherapy (Frank \& Gunderson, 1990) but not in CBTp studies (Dunn et al., 2006; Lecomte et al., 2015). The results were less consistent for Acceptance and Commitment Therapy (Staring et al., 2011, White et al., 2011), although it is of note that the 
larger of these two trials (Staring et al, 2011) did identify a significant association between client-rated TA and improvement in psychotic symptoms. A mixed therapy of CBTp and Motivational interviewing (Berry et al., 2015) only showed an association between therapistrated TA and change in psychotic symptoms.

\section{Therapeutic Alliance \& Additional Outcomes}

Other Symptoms and Associated Difficulties: Depression, Insight, Substance Use, Cognition \& Physical Health Behaviours. No analysis that investigated associations with depression identified a significant effect (four analyses in three studies). One out of two studies identified a significant, positive relationship between TA and client insight (33.3\% of analyses). There was limited evidence for associations with substance use (one significant association identified across four analyses from two studies; 25\%). Two of three studies (50\% of four analyses) indicated that TA during therapy was positively related to cognition (i.e. working memory, non-verbal memory and overall cognitive performance). Two studies examined the potential link between TA and physical health behaviours (i.e. \% weight loss, time spent walking each week and number of cigarettes smoked daily); none of the six analyses demonstrated a significant relationship.

Hospitalisation. TA during psychological therapy was linked to hospital use in two out of five analyses across two studies (40\%). Specifically, these two significant findings related to therapist-rated TA as associated with the risk of readmission to hospital (Frank \& Gunderson, 1990) and observer rating of relatives' TA during family therapy and days until client rehospitalisation (Smerud \& Rosenfarb, 2008).

Positive Recovery Measures. Four studies investigated TA and overall client functioning as an outcome from therapy; two out of eight analyses (25\%) found a significant and positive relationship. One out of four analyses ( $25 \%$ across three studies) demonstrated a significant positive relationship between TA and social functioning at follow-up specifically. 
TA was significantly related to improvement in self-esteem over time in one of four analyses, conducted across two studies (25\%). Two studies examined the impact of TA during therapy on overall "mental health recovery" measures. One of the two analyses indicated a significant and positive relationship.

\section{Discussion}

This review investigated the association between TA and therapy process as well as therapy outcomes during psychological therapies for psychosis. Meta-analyses revealed that the effect size for the association between TA and client engagement in therapy was "moderate" 8 when alliance was rated by client $(r=0.36)$ and therapist $(r=0.40)$. The association with change in global symptomatology was "moderate" across therapist $(r=0.24)$ and client $(r=0.29)$ perspectives, and within the "small"-to-"moderate" range for TA and change in psychotic symptoms (Therapist-rated TA, $r=0.30$; Client-rated, $r=0.17$ ).

$\mathrm{R}^{2}$ values indicated that client- and therapist-rated TA accounted for $13 \%$ and $16 \%$ of the variation in engagement, respectively. $\mathrm{R}^{2}$ values for the association between TA and change in either global or psychotic symptoms ranged from $0.03-0.09$. This suggests that, within the current meta-analyses, 3-9\% of the variation in symptom change over the course of psychological therapy could be attributed to TA during therapy. These conclusions about the proportion of variation accounted for by TA must be reported with caution because they represent findings from bivariate, correlational meta-analyses. Therefore, they cannot be interpreted as indicating a causal pathway or taking any third variable effect into account.

The results of these meta-analyses are broadly in keeping with the effect sizes observed in existing TA-outcome meta-analytic reviews with non-psychotic samples (Flückiger et al., 2018; Horvath \& Symonds, 1991; Martin \& Garske, 2000) and extend the qualitative review

\footnotetext{
${ }^{8}$ Cohen's (1992) conventions for "small" $(\rho=0.1)$, "medium" $(\varrho=0.3)$ and "large" $(\rho=0.5)$ correlation coefficients are applied to estimate the size of the overall effect.
} 
in non-affective psychosis by Shattock et al. (2018). The associations reported as well as the observed consistency with existing reviews are based on a small number of studies. In particular, future replication of our findings would be needed before a common role for TA in psychological therapy across client groups could be asserted.

\section{Considering Potential Moderating Factors}

According to Emsley and colleagues (Emsley et al., 2010), a "moderator" effect would be present in the context of the current review if variation in the TA affected the strength of at least one part of the causal pathway from psychological therapy to treatment outcome. Below, we consider therapy duration, timing of outcome follow-up assessment and therapeutic modality as three potential moderators for the association between TA and process or outcome in psychosis. Analysing moderator variables statistically was beyond the scope of the current review and therefore these remain tentative observations.

\section{Therapy Duration and Timing of T2 Outcome Assessment}

The observed potential moderating role for length of therapy and/or length of time between baseline and T2 assessment was specific to the correlation between TA and change in psychotic symptoms. The papers that reported a significant effect examined longer duration of therapy as well as capturing change in outcome over a longer follow-up period than those that reported a null result. It is plausible, for instance, that a longer period of trustbuilding would be needed before experiences such as paranoid ideation, delusions and voices could be discussed openly and become amenable to lasting change (e.g. Wood et al., 2015).

We must also consider time as a potential confounder of the hypothesised TA-outcome relationship. An independent link between a longer course of therapy and improved outcome due to a greater therapy "dose" could be hypothesised. However, one of the included papers (Goldsmith et al., 2015) indicated that number of therapy sessions attended only predicted symptomatic improvement where there was a stronger TA. A longer period before follow-up 
outcome assessment could highlight improved outcome as service users have had more opportunity to integrate therapy concepts within their everyday lives. It may be that, irrespective of the strength of the alliance, there is a link between the timing of followup assessment and improvement in psychotic symptoms; this is a limitation of the current review that will require further research.

\section{Therapeutic Modality}

A preliminary exploration of therapeutic modality as a potential moderator for the TAoutcome association did not indicate an interpretable pattern, especially given the small number of included studies. Individual psychotherapy was the modality most consistently linked to a significant association. This therapeutic model conceptualises the TA as a source of insight into the client's way of relating to others. A strong TA may support people with psychosis to continue attending sessions despite the activation of their defences during therapy (e.g. Horvath \& Luborsky, 1993; Horvath et al., 2011). However, we cannot make clear inferences from the observed pattern as individual psychotherapy was represented by a single study that reported multiple outcomes. Similarly, the lack of significant associations between TA and symptom outcomes in "pure" CBTp (i.e. not combined with techniques from other modalities) was derived from just three studies, one of which did report an association between therapist-rated TA and engagement.

It is plausible that the TA could have an especially important role in shaping engagement with therapy in CBTp. Service users report higher levels of satisfaction with this modality where they have positive perceptions of their therapist (Lawlor et al., 2017). There may be a further role for the TA in instilling service users with hope; those who perceive that their difficulties can improve through therapy are more likely to attend and achieve progress through their CBTp sessions (Freeman et al., 2013). The above hypotheses highlight the need 
for further research within a larger pool of studies to clarify any variation in the relationship between TA and both therapeutic engagement and outcome by therapy type.

\section{Strengths and Limitations of the Current Review}

The current review is the first to synthesize the evidence for the association between the TA and both therapy engagement and change in outcome for psychosis quantitatively as well as qualitatively. We applied a comprehensive data-sourcing approach by (1) including proactive contact with research groups (see Figure 1) and (2) ensuring that we included eligible records from the grey literature in our systematic search. The goal of the latter criterion was to guard against the file-drawer phenomenon whereby the published literature around a subject area is skewed towards positive findings, rather than those studies that identify null results. This review also tailored an existing NIH tool to assess methodological quality rigorously. Collectively, the final papers were methodologically strong in their use of well-supported measures (TA, engagement and outcome) as well as the clearly described and manualized therapies they investigated.

For the meta-analyses, we synthesised findings only where there was sufficient methodological consistency to allow a meaningful result (Cuijpers, 2016), reducing the number of studies included to 13. It is important to acknowledge the need for tentative interpretations given this small number of studies. All but two of the included studies reported that antipsychotic medication was prescribed in addition to psychological therapy, but just three reported the degree to which participants adhered to this medication. Therefore, we cannot assume that the current findings would be representative of the association between TA and outcome in the context of psychological therapy alone (i.e. without medication). We were also unable to account for the potential moderator effect of medication adherence on this role for the alliance. 
The current systematic review examined a range of outcome measures, provided that each measure was included in at least two studies, regardless of whether the study authors had identified them to be primary targets/outcomes of the study. The goal of this approach was to complete a broad, meaningful synthesis of the relationship between TA and a range of indices of recovery in psychosis. A potential limitation of this decision could have been that it masked the strength of the relationship between TA and change in the intervention's primary target, however the alternative summary grid in Supplementary Material D would not appear to confirm this. Although our eligibility criteria allowed for a broad definition of therapy outcome and we synthesised associations between TA and therapeutic engagement, the final meta-analyses collated predominantly symptom-focused data. To an extent, this review may then present a reductionist view of outcome rather than the multi-faceted definition of recovery in psychosis that service users identify themselves (Pitt et al., 2007).

The methodological quality assessment highlighted three potential sources of bias in the current review. First, just four of the 24 included papers reported studies that were designed originally to detect TA-outcome associations, while the remainder reported secondary analyses from existing trials with a different research question. One study reported conducting a power calculation to ensure analyses had sufficient power to detect the relevant effect. When these patterns are taken together, we can infer a risk that a number of the final papers may have reported studies that were under-powered to detect a specific TA-therapy process/outcome effect.

Second, our conclusions may not be representative of service users who are at risk of the poorest therapy outcomes (i.e. experience lower quality TA and drop out of therapy). Six of the 24 studies received the highest quality rating because they reported a $\leq 20 \%$ attrition rate and/or took the participants who were lost to follow-up into account in their analyses. Three studies received a "low" rating because, for example, the sample was selected 
retrospectively to include only those who completed a full course of therapy. Therefore, the nature of the review question and the analysis strategy of selected studies may have introduced a risk of attrition bias.

Third, two of the papers that reported significant associations between therapist-rated TA and change in symptoms ([global symptoms] Mulligan et al., 2014; Frank \& Gunderson, 1990 and [psychotic symptoms] Frank \& Gunderson, 1990) were included in the metaanalysis stage but identified to be at risk of bias. Frank and Gunderson applied a factor- and cluster analysis strategy to distil items on seven established measures into a briefer set of measures to track change in symptomatology. Thus, although they used existing measures, their final approach to evaluating therapeutic outcome was not yet validated. Mulligan and colleagues' outcome measure looked to the therapist themselves to make a subjective judgement about degree of change in global symptoms. Therapists could have been motivated to report symptomatic improvement on such measures to demonstrate the positive impact of their clinical work.

We drew on the precedence criterion for inferring causality (Barker et al. 2016) by specifying that eligible papers must assess TA during therapy and outcome at a subsequent time-point. We also examined change in symptoms over time to be better able to venture that TA quality facilitates symptomatic improvement, rather than being only a by-product of it (Constantino et al., 2007). However, applying correlational meta-analyses means that any inference regarding a TA-to-outcome relationship from the current correlational metaanalyses must be made cautiously. Just as strong alliance could predict symptom reduction and enhanced therapeutic engagement, so clients are likely to be better able to establish an alliance once they have seen a reduction in their symptoms and/or attended more sessions of therapy (DeRubeis et al., 2005). Similarly, although the studies included in the meta-analyses offer clarity by operationalising engagement as number of sessions attended/missed or time 
spent practicing therapy tasks specifically, in practise, it may be difficult to disentangle the distinction between alliance versus how far the client feels engaged in therapy.

Alliance also continues to evolve throughout therapy according to the challenges that client and clinician face and resolve together (Elvins \& Green, 2008; Horvath et al., 1993). Future research is needed elucidate the mechanism(s) of effect behind the overarching alliance-outcome associations observed here in psychosis; a notable gap in the literature for service users with a serious mental illness in general (Hasson-Ohayon et al., 2017).

\section{Implications for Future Research}

Many of the papers included in this review conducted secondary analysis of data from trials designed to examine the comparative efficacy of a psychological therapy relative to another modality or standard care as their primary research question. There could be a risk that researchers were motivated to find support for the focal therapy's specific effect, over and above the impact of alliance as a non-specific factor (de Felice et al., 2019; Luborsky, 1995; Marcus et al., 2014). In line with Priebe and McCabe's (2006) conclusions, the current review underscores the need for more original studies in this field, with a central place for the alliance-outcome relationship in the research questions and analyses.

The current review reported similar outcome associations with client and therapist TA ratings, in line with existing research showing that the significant impact of alliance on outcome from psychotherapy is independent of whose perspective is captured (Horvath et al., 2011). However, given that some studies suggest subtle differences between client and therapist evaluations of the alliance in other presentations (e.g. Croft \& Watson, 2019), further research on psychological interventions for psychosis should explore the impact of any such discrepancies, as well as the potential for distinct perceptions regarding the role of the TA in therapy. 


\section{Implications for Clinical Practice}

The evidence base reviewed here established that service users with psychosis can develop a TA and that there is a significant association between the quality of the relationship and therapeutic engagement as well as symptomatic improvement. This could suggest that TA is important in enabling the efficacy of therapy; a critical consideration for service users with psychosis as they may be emotionally avoidant or mistrustful of the therapist, especially at the outset of therapy (Rollinson et al., 2008). Although alliance can be threatened by challenges associated with the experience of psychosis, it can still be formed where clinicians are sensitive to the needs of this group (Hasson-Ohayon et al., 2017). Clinicians must consider how they interact with these service users carefully throughout the course of their work if they are to build a therapeutic relationship (Collip et al., 2011).

Routine assessment of the TA during psychological therapy may be beneficial to detect potential ruptures as they arise (Wood et al., 2015) and service users higher in paranoia may require greater interpersonal responsiveness before they can develop trust (Fornells-Ambrojo et al., 2016). Chadwick (2006) advocates for a service user-tailored, radically collaborative approach when working with psychosis, rather than focusing on how therapy "should" look. For instance, it could be advisable for therapists to delay introducing specific techniques until they feel confident that the TA has developed to a sufficient level through engagement groundwork (Rollinson et al., 2008). These perspectives are consistent with the findings of the current review: service users can engage with psychological therapy and see an improvement in their symptoms when clinicians manage to build a TA, despite the barriers presented by psychosis. 


\section{References}

* References included in the review

*Andrews, M., Baker, A. L., Halpin, S. A., Lewin, T. J., Richmond, R., Kay-Lambkin, F. J., Filia, S. L., Castle, D., Williams, J. M., Clark, V., \& Callister, R. (2016). Early therapeutic alliance, treatment retention, and 12-month outcomes in a healthy lifestyles intervention for people with psychotic disorders. Journal of Nervous and Mental Disease, 204(12), 894-902. https://doi.org/10.1097/NMD.0000000000000585

Barker, C., Pistrang, N., \& Elliott, R. (2016). Research Methods in Clinical Psychology: An introduction for students and practitioners ( $3^{\text {rd }}$ Edition). John Wiley \& Sons, Ltd.

Battle, C. C., Imber, S. D., Hoehn-Saric, R., Stone, A. R., Nash, E. R., \& Frank, J. D. (1966). Target complaints as criteria of improvement. American Journal of Psychotherapy, 20(1), 184-192.

https://doi.org/10.1176/appi.psychotherapy.1966.20.1.184

Berry, K., Barrowclough, C., \& Wearden, A. (2007) $)^{\mathrm{a}}$. A review of the role of adult attachment style in psychosis: Unexplored issues and questions for further research. Clinical Psychology Review, 27(4), 458-475. https://doi.org/10.1016/j.cpr.2006.09.006

Berry, K., Palmer, T., Gregg, L., Barrowclough, C., \& Lobban, F. (2018). Attachment and therapeutic alliance in psychological therapy for people with recent onset psychosis who use cannabis. Clinical Psychology \& Psychotherapy, 25(3), 440-445.

https://doi.org/10.1002/cpp.2178

*Berry, K., Gregg, L., Hartwell, R., Haddock, G., Fitzsimmons, M., \& Barrowclough, C. (2015). Therapist-client relationships in a psychological therapy trial for psychosis and substance misuse. Drug and Alcohol Dependence, 152, 170-176. https://doi.org/10.1016/j.drugalcdep.2015.04.006 
*Berry, K., Gregg, L., Lobban, F., \& Barrowclough, C. (2016). Therapeutic alliance in psychological therapy for people with recent onset psychosis who use cannabis. Comprehensive Psychiatry, 67, 73-80. https://doi.org/10.1016/j.comppsych.2016.02.014

Berry, K., Wearden, A., \& Barrowclough, C. (2007) ${ }^{\text {b }}$ Adult attachment styles and psychosis: an investigation of associations between general attachment styles and attachment relationships with specific others. Social Psychiatry and Psychiatric Epidemiology, 42(12), 972-976. https://doi.org/10.1007/s00127-007-0261-5

Blackburn, C., Berry, K., \& Cohen, K. (2010). Factors correlated with client attachment to mental health services. The Journal of Nervous and Mental Disease, 198(8), 572-575. https://doi.org/10.1097/NMD.0b013e3181ea16d6

Bordin, E.S. (1979). The generalizability of the psychoanalytic concept of the working alliance. Psychotherapy: Theory, Research \& Practice. 16(3), 252-260. https://doi.org/10.1037/h0085885

Bordin, E. S. (1980). Of human bonds that bind or free. In Annual Meeting of the Society for Psychotherapy Research, Pacific Grove, CA.

Bowlby, J. (1988). A secure base: Parent-child attachment and healthy human development. Routledge.

*Browne, J., Mueser, K. T., Meyer-Kalos, P., Gottlieb, J. D., Estroff, S. E., \& Penn, D. L. (2019). The therapeutic alliance in individual resiliency training for first episode psychosis: Relationship with treatment outcomes and therapy participation. Journal of Consulting and Clinical Psychology, 87(8), 734. https://doi.org/10.1037/ccp0000418

Carr, S. C., Hardy, A., \& Fornells-Ambrojo, M. (2017). Relationship between attachment style and symptom severity across the psychosis spectrum: A metaanalysis. Clinical Psychology Review, 59, 145-158.

https://doi.org/10.1016/j.cpr.2017.12.001 
Cella, M., Preti, A., Edwards, C., Dow, T., \& Wykes, T. (2017). Cognitive remediation for negative symptoms of schizophrenia: A network meta-analysis. Clinical Psychology Review, 52, 43-51. https://doi.org/10.1016/j.cpr.2016.11.009

*Cella, M., \& Wykes, T. (2017). The nuts and bolts of cognitive remediation: exploring how different training components relate to cognitive and functional gains. Schizophrenia Research. https://doi.org/10.1016/j.schres.2017.09.012

Chadwick, P. (2006). Person-based cognitive therapy for distressing psychosis. John Wiley \& Sons, Ltd.

Cohen, J. (1992). A power primer. Psychological Bulletin, 112 (1), 155-159.

Collip, D., Oorschot, M., Thewissen, V., Van Os, J., Bentall, R., \& Myin-Germeys, I. (2011). Social world interactions: how company connects to paranoia. Psychological Medicine, 41(5), 911-921. https://doi.org/10.1017/S0033291710001558

Constantino, M. J., Coyne, A. E., Luukko, E. K., Newkirk, K., Bernecker, S. L., Ravitz, P., \& McBride, C. (2017). Therapeutic alliance, subsequent change, and moderators of the alliance-outcome association in interpersonal psychotherapy for depression. Psychotherapy, 54(2), 125-135. https://doi.org/10.1037/pst0000101

Craig, T. K., Rus-Calafell, M., Ward, T., Leff, J. P., Huckvale, M., Howarth, E., Emsley, R., \& Garety, P. (2018). AVATAR therapy for auditory verbal hallucinations in people with psychosis: a single-blind, randomised controlled trial. The Lancet Psychiatry, 5(1), 3140. https://doi.org/10.1016/S2215-0366(17)30427-3

Croft, R. L., \& Watson, J. (2019). Student clinicians' and clients' perceptions of the therapeutic alliance and outcomes in stuttering treatment. Journal of Fluency Disorders, 61, 105709.

Cuijpers, P. (2016). Meta-analysis in mental health research. A practical guide. Amsterdam: 
Vrije Universiteit Amsterdam: Faculty of Behavioural and Movement Sciences. https://indd.adobe.com/view/5fc8f9a0-bf1e-49d3-bf5f-a40bfe5409e0. Last accessed $13 / 06 / 20$.

*Davis, L. W., \& Lysaker, P. K. (2007). Therapeutic alliance and improvements in work performance over time in patients with schizophrenia. Journal of Nervous and Mental Disease, 195(4), 353-357. https://doi.org/10.1097/01.nmd.0000261954.36030.a1

*Dunn, H., Morrison, A. P., \& Bentall, R. P. (2006). The Relationship between Patient Suitability, Therapeutic Alliance, Homework Compliance and Outcome in Cognitive Therapy for Psychosis. Clinical Psychology \& Psychotherapy, 13(3), 145-152. https://doi.org/10.1002/cpp.481

Elvins, R., \& Green, J. (2008). The conceptualization and measurement of therapeutic alliance: An empirical review. Clinical Psychology Review, 28(7), 1167-1187. https://doi.org/10.1016/j.cpr.2008.04.002

Emsley, R., Dunn, G., \& White, I. R. (2010). Mediation and moderation of treatment effects in randomised controlled trials of complex interventions. Statistical Methods in Medical Research, 19(3), 237-270. https://doi.org/10.1177/0962280209105014

de Felice, G., Giuliani, A., Halfon, S., Andreassi, S., Paoloni, G., \& Orsucci, F. F. (2019). The misleading Dodo Bird verdict. How much of the outcome variance is explained by common and specific factors?. New Ideas in Psychology, 54, 50-55.

https://doi.org/10.1016/j.newideapsych.2019.01.006

Flückiger, C., Del Re, A., Wampold, B., \& Horvath, A. (2018). The Alliance in Adult Psychotherapy. Psychotherapy, 55(4), 316-340. https://doi.org/10.1037/pst0000172 Fornells-Ambrojo, M., Elenbaas, M., Barker, C., Swapp, D., Navarro, X., Rovira, A., ... \& Slater, M. (2016). Hypersensitivity to contingent behavior in paranoia: A new virtual reality paradigm. The Journal of Nervous and Mental Disease, 204(2), 148-152. 


\section{https://doi.org/10.1097/NMD.0000000000000414}

*Frank, A. F., \& Gunderson, J. G. (1990). The role of the therapeutic alliance in the treatment of schizophrenia: Relationship to course and outcome. Archives of General Psychiatry, 47(3), 228-236. https://doi.org/10.1001/archpsyc.1990.01810150028006

Freeman, D., Dunn, G., Garety, P., Weinman, J., Kuipers, E., Fowler, D., Jolley, S., \& Bebbington, P. (2013). Patients' beliefs about the causes, persistence and control of psychotic experiences predict take-up of effective cognitive behaviour therapy for psychosis. Psychological Medicine, 43, 269-277. https://doi.org/10.1017/S0033291712001225

Friedman, L. (1969). The Therapeutic Alliance. International Journal of Psychoanalysis, 50, 139-153. Retrieved from: https://www.pep-web.org/document.php?id=ijp.050.0139a

Freud, S. (1913). On beginning the treatment. In The Standard Edition of the Complete Psychological Works of Sigmund Freud, Volume 12 (Strachey, J.). Hogarth Press.

*Goldsmith, L., Lewis, S., Dunn, G., \& Bentall, R. (2015). Psychological treatments for early psychosis can be beneficial or harmful, depending on the therapeutic alliance: An instrumental variable analysis. Psychological Medicine, 45(11), 2365-2373. https://doi.org/10.1017/S003329171500032X

Gumley, A. I., Taylor, H. E. F., Schwannauer, M., \& MacBeth, A. (2014). A systematic review of attachment and psychosis: measurement, construct validity and outcomes. Acta Psychiatrica Scandinavica, 129(4), 257-274.

$\underline{\text { https://doi.org/10.1111/acps. } 12172}$

Haddock, G., McCarron, J., Tarrier, N., \& Faragher, E. B. (1999). Scales to measure dimensions of hallucinations and delusions: The Psychotic Symptom Rating Scales (PSYRATS). Psychological Medicine, 29(4), 879-889.

https://doi.org/10.1017/s0033291799008661 
*Hammond, K. (2004). Treatment Integrity, Therapeutic Alliance and Outcome: An evaluation of the relationship in cognitive behaviour therapy and befriending for psychosis [Unpublished Doctoral dissertation] University of East Anglia. Retrieved from https://ethos.bl.uk/OrderDetails.do?uin=uk.bl.ethos.426870

*Hargreaves, A., Dillon, R., Castorina, M., Furey, E., Walsh, J., Fitzmaurice, B., Hallahan, B., Corvin, A., Roberston, I., \& Donohoe, G. (2018). Predictors of adherence to low support, computerised, cognitive remediation training in psychosis. Psychosis, 10(4), 298-306. https://doi.org/10.1080/17522439.2018.1522542

*Hassan, S., Ganguli, R., Flett, G., Suleiman, A., \& Hewitt, P. (2014). Poster\# S213 PERFECTIONISM AND WORKING ALLIANCE IN A COGNITIVEBEHAVIORAL INTERVENTION FOR WEIGHT LOSS IN PSYCHOTIC ILLNESS. Schizophrenia Research, (153), S166. https://doi.org/10.1016/S09209964(14)70492-X

Hasson-Ohayon, I., Kravetz, S., \& Lysaker, P. H. (2017). The special challenges of psychotherapy with persons with psychosis: intersubjective metacognitive model of agreement and shared meaning. Clinical Psychology \& Psychotherapy, 24(2), 428-440. https://doi.org/10.1002/cpp.2012

Hayward, M., Jones, A. M., Bogen-Johnston, L., Thomas, N., \& Strauss, C. (2017). Relating Therapy for distressing auditory hallucinations: a pilot randomized controlled trial. Schizophrenia Research, 183, 137-142. https://doi.org/10.1016/j.schres.2016.11.019

*Hicks, A. L., Deane, F. P., \& Crowe, T. P. (2012). Change in working alliance and recovery in severe mental illness: An exploratory study. Journal of Mental Health, 21(2), 127134. https://doi.org/10.3109/09638237.2011.621469

Higgins, J. P. T., \& Green, S. (Eds.). Cochrane Handbook for Systematic Reviews of 
Interventions Version 5.1.0 [Updated March 2011]. The Cochrane Collaboration, 2011. www.handbook.cochrane.org. Last accessed 29/12/20.

Higgins, J. P., Thompson, S. G., Deeks, J. J., \& Altman, D. G. (2003). Measuring inconsistency in meta-analyses. British Medical Journal, 327(7414), 557. https://doi.org/10.1136/bmj.327.7414.557

Horvath, A. O., Del Re, A. C., Flückiger, C., \& Symonds, D. (2011). Alliance in individual psychotherapy. Psychotherapy, 48(1), 9-16. https://doi.org/10.1037/a0022186

Horvath, A., Gaston, L., \& Luborsky, L. (1993). The therapeutic alliance and its measures. In N. E. Miller, L. Luborsky, J. P. Barber, \& J. P. Docherty (Eds.), Psychodynamic Treatment Research (pp. 247-273). Basic Books.

Horvath, A. O., \& Greenberg, L. S. (1989). Development and validation of the Working Alliance Inventory. Journal of Counseling Psychology, 36(2), 223-233. https://doi.org/10.1037/0022-0167.36.2.223

Horvath, A. O., \& Luborsky, L. (1993). The role of the therapeutic alliance in psychotherapy. Journal of Consulting and Clinical Psychology, 61(4), 561-573. https://doi.org/10.1037/0022-006X.61.4.561

Horvath, A. O., \& Symonds, B. D. (1991). Relation between working alliance and outcome in psychotherapy: A meta-analysis. Journal of Counseling Psychology, 38(2), 139-149. https://doi.org/10.1037/0022-0167.38.2.139

*Huddy, V., Reeder, C., Kontis, D., Wykes, T., \& Stahl, D. (2012). The effect of working alliance on adherence and outcome in cognitive remediation therapy. Journal of Nervous and Mental Disease, 200(7), 614-619. https://doi.org/10.1097/NMD.0b013e31825bfc31

Huibers, M. J., \& Cuijpers, P. (2015). Common (nonspecific) factors in psychotherapy. The Encyclopedia of Clinical Psychology. John Wiley \& Sons, Ltd. 
*Johnson, D. P., Penn, D. L., Bauer, D. J., Meyer, P., \& Evans, E. (2008). Predictors of the therapeutic alliance in group therapy for individuals with treatment-resistant auditory hallucinations. British Journal of Clinical Psychology, 47(2), 171-183 https://doi.org/10.1348/014466507X241604

*Jones, S., Brush, L., Shagan, D., Thime, W., Adelsberger, P., Grealy, M., Haber, L. C., Peters, E., Pearlson, G., Twamley, E. W., Choi, J., \& Twamley, E. (2017). SU35. Treatment Outcome in Compensatory Cognitive Training for Schizophrenia: Therapeutic Alliance vs Learning Potential. Schizophrenia Bulletin, 43(suppl_1), S173-S174. https://doi.org/10.1093/schbul/sbx024.033

Kay, S. R., Fiszbein, A., \& Opfer, L. A. (1987). The positive and negative syndrome scale (PANSS) for schizophrenia. Schizophrenia Bulletin, 13(2), 261-276. https://doi.org/10.1093/schbul/13.2.261

Lambert, M. J. (2013). The efficacy and effectiveness of psychotherapy. In M. J. Lambert (Ed.), Bergin and Garfield's Handbook of Psychotherapy and Behavior Change ( $6^{\text {th }}$ Edition). John Wiley \& Sons, Ltd.

Lawlor, C., Sharma, B., Khondoker, M., Peters, E., Kuipers, E., \& Johns, L. (2017). Service user satisfaction with cognitive behavioural therapy for psychosis: Associations with therapy outcomes and perceptions of the therapist. British Journal of Clinical Psychology, 56(1), 84-102. https://doi.org/10.1111/bjc.12122

*Lecomte, T., Laferrière-Simard, M.-C., \& Leclerc, C. (2012). What does the alliance predict in group interventions for early psychosis? Journal of Contemporary Psychotherapy, 42(2), 55-61. https://doi.org/10.1007/s10879-011-9184-2

*Lecomte, T., Leclerc, C., Wykes, T., Nicole, L., \& Abdel Baki, A. (2015). Understanding process in group cognitive behaviour therapy for psychosis. Psychology and Psychotherapy: Theory, Research and Practice, 88(2), 163-177. 
https://doi.org/10.1111/papt.12039

Lee, W., \& Hotopf, M. (2012). Critical appraisal: Reviewing scientific evidence and reading academic papers. In Wright, P., Stern, J., \& Phelan, M. (Eds.), Core Psychiatry (3 ${ }^{\text {rd }}$ Edition). Saunders Ltd. https://doi.org/10.1016/B978-0-7020-3397-1.00010-0

Lincoln, T. M., Ziegler, M., Mehl, S., Kesting, M.-L., Lüllmann, E., Westermann, S., \& Rief, W. (2012). Moving from efficacy to effectiveness in cognitive behavioral therapy for psychosis: A randomized clinical practice trial. Journal of Consulting and Clinical Psychology, 80(4), 674-686. https://doi.org/10.1037/a0028665

Luborsky, L. (1995). Are Common Factors Across Different Psychotherapies the Main Explanation for the Dodo Bird Verdict That "Everyone Has Won So All Shall Have Prizes"?. Clinical Psychology: Science and Practice, 2(1), 106-109. https://doi.org/10.1111/j.1468-2850.1995.tb00033.x

Marcus, D. K., O'Connell, D., Norris, A. L., \& Sawaqdeh, A. (2014). Is the Dodo bird endangered in the 21 st century? A meta-analysis of treatment comparison studies. Clinical Psychology Review, 34(7), 519-530.

https://doi.org/10.1016/j.cpr.2014.08.001

Martin, D. J., Garske, J. P., \& Davis, M. K. (2000). Relation of the therapeutic alliance with outcome and other variables: A meta-analytic review. Journal of Consulting and Clinical Psychology, 68(3), 438-450.

https://doi.org/10.1037/0022-006X.68.3.438

McGurk, S. R., Twamley, E. W., Sitzer, D. I., McHugo, G. J., \& Mueser, K. T. (2007). A meta-analysis of cognitive remediation in schizophrenia. American Journal of Psychiatry, 164(12), 1791-1802. https://doi.org/10.1176/appi.ajp.2007.07060906

Mehl, S., Werner, D., \& Lincoln, T. M. (2015). Does Cognitive Behavior Therapy 
for psychosis (CBTp) show a sustainable effect on delusions? A metaanalysis. Frontiers in Psychology, 6, 1450. https://doi.org/10.3389/fpsyg.2015.01450

Meichenbaum, D., \& Lilienfeld, S. O. (2018). How to spot hype in the field of psychotherapy: A 19-item checklist. Professional Psychology: Research and Practice, 49(1), 22-30. https://doi.org/10.1037/pro0000172

Miller, W. R., \& Rollnick, S. (2012). Motivational Interviewing: Helping people change. New York: Guilford Press.

Milne, D., Wharton, S., James, I., \& Turkington, D. (2006). Befriending versus CBT for schizophrenia: a convergent and divergent fidelity check. Behavioural and Cognitive Psychotherapy, 34(1), 25-30. https://doi.org/10.1017/S1352465805002456

Moyers, T. B., Miller, W. R., \& Hendrickson, S. M. (2005). How does motivational interviewing work? Therapist interpersonal skill predicts client involvement within motivational interviewing sessions. Journal of Consulting and Clinical Psychology, 73(4), 590. https://doi.org/10.1037/0022-006X.73.4.590

*Mulligan, J., Haddock, G., Hartley, S., Davies, J., Sharp, T., Kelly, J., Neil, S. T., Taylor, C. D. J., Welford, M., Price, J., Rivers, Z., \& Barrowclough, C. (2014). An exploration of the therapeutic alliance within a telephone-based cognitive behaviour therapy for individuals with experience of psychosis. Psychology and Psychotherapy: Theory, Research and Practice, 87(4), 393-410.

https://doi.org/10.1111/papt.12018

The National Institutes of Health (2014). Quality assessment tool for before-after (pre-post) studies with no control group. https://www.nhlbi.nih.gov/health-topics/studyquality-assessment-tools. Last accessed 13/06/20.

Orwin, R. G. (1983). A fail-safe N for effect size in meta-analysis. Journal of Educational Statistics, 8(2), 157-159. https://doi.org/10.3102/10769986008002157 
Pharoah, F., Mari, J. J., Rathbone, J., \& Wong, W. (2010). Family intervention for schizophrenia. The Cochrane Library, 12, 1-108. https://doi.org/10.1002/14651858.CD000088.pub2

Pitt L., Kilbride M., Nothard S., Welford M., \& Morrison A. P. (2007). Researching recovery from psychosis: A user-led project. Psychiatry Bulletin, 31, 55-60. https://doi.org/10.1192/pb.bp.105.008532

Priebe, S., \& McCabe, R. (2006). The therapeutic relationship in psychiatric settings. Acta Psychiatrica Scandinavica, 113(s429), 69-72. https://doi.org/10.1111/j.1600-0447.2005.00721.x

Rogers, C. R. (1957). The necessary and sufficient conditions of therapeutic personality change. Journal of Consulting Psychology, 21(2), 95-103.

https://doi.org/10.1037/h0045357

Rollinson, R., Smith, B., Steel, C., Jolley, S., Onwumere, J., Garety, P. A., Kuipers, E., Freeman, D., Bebbington, P. E., Dunn, G., Startup, M., \& Fowler, D. (2008). Measuring adherence in CBT for psychosis: a psychometric analysis of an adherence scale. Behavioural and Cognitive Psychotherapy, 36(2), 163-178. https://doi.org/10.1017/S1352465807003980

Rosenthal, R. (1979) The "file drawer problem" and tolerance for null results, Psychological Bulletin, Vol. 86, No. 3, 838-641.

Rosenzweig, S. (1936). Some implicit common factors in diverse methods of psychotherapy: "At last the Dodo said, 'Everybody has won and all must have prizes."' American Journal of Orthopsychiatry, 6, 412-415. https://doi.org/10.1111/j.1939$\underline{0025.1936 . t b 05248 . x}$

Sensky, T., Turkington, D., Kingdon, D., Scott, J.L., Scott, J., Siddle, R., O'Carroll, 
M., \& Barnes, T. R. E. (2000). A randomised controlled trial of cognitivebehavioural therapy for persistent symptoms in schizophrenia resistant to medication. Archives of General Psychiatry, 57, 165-172. https://doi.org/10.1001/archpsyc.57.2.165 Shattock, L., Berry, K., Degnan, A., \& Edge, D. (2018). Therapeutic alliance in psychological therapy for people with schizophrenia and related psychoses: A systematic review. Clinical Psychology \& Psychotherapy, 25(1), e60-e85. https://doi.org/10.1002/cpp.2135

Siddaway, A. P., Wood, A. M., \& Hedges, L. V. (2019). How to do a systematic review: a best practice guide for conducting and reporting narrative reviews, meta-analyses, and meta-syntheses. Annual Review of Psychology, 70, 747-770. $\underline{\text { https://doi.org/10.1146/annurev-psych-010418-102803 }}$

*Smerud, P. E., \& Rosenfarb, I. S. (2008). The therapeutic alliance and family psychoeducation in the treatment of schizophrenia: An exploratory prospective change process study. Journal of Consulting and Clinical Psychology, 76(3), 505. https://doi.org/10.1037/0022-006X.76.3.505

*Staring, A. B., van der Gaag, M., \& Mulder, C. L. (2011). Recovery style predicts remission at one-year follow-up in outpatients with schizophrenia spectrum disorders. Journal of Nervous and Mental Disease, 199(5), 295-300. https://doi.org/10.1097/NMD.0b013e3182174e97

*Startup, M., Wilding, N., \& Startup, S. (2006). Patient treatment adherence in cognitive behaviour therapy for acute psychosis: The role of recovery style and working alliance. Behavioural and Cognitive Psychotherapy, 34(2), 191-199. https://doi.org/10.1017/S1352465805002535

*Svensson, B., \& Hansson, L. (1999). Therapeutic alliance in cognitive therapy for 
schizophrenic and other long-term mentally ill patients: development and relationship to outcome in an in-patient treatment programme. Acta Psychiatrica Scandinavica, 99(4), 281-287. https://doi.org/10.1111/j.1600-0447.1999.tb07226.x

Tarrier, N., Beckett, R., Harwood, S., Baker, A., Yusupoff, L., \& Ugarteburu, I. (1993). A trial of two cognitive-behavioural methods of treating drug-resistant residual psychotic symptoms in schizophrenic patients: I. Outcome. The British Journal of Psychiatry, 162(4), 524-532. https://doi.org/10.1192/bjp.162.4.524

Tarrier, N., Yusupoff, L., Kinney, C., McCarthy, E., Gledhill, A., Haddock, G., \&, Morris, J. (1998). Randomised controlled trial of intensive cognitive behaviour therapy for patients with chronic schizophrenia. The British Medical Journal, 317(7154), 303-307. https://doi.org/10.1136/bmj.317.7154.303

Turner, D. T., McGlanaghy, E., Cuijpers, P., van der Gaag, M., Karyotaki, E., \& MacBeth, A. (2017). A meta-analysis of social skills training and related interventions for psychosis. Schizophrenia Bulletin, 44(3), 475-491. https://doi.org/10.1093/schbul/sbx146

van der Gaag, M., Valmaggia, L. R., \& Smit, F. (2014). The effects of individually tailored formulation-based cognitive behavioural therapy in auditory hallucinations and delusions: A meta-analysis. Schizophrenia Research, 156(1), 30-37.

https://doi.org/10.1016/j.schres.2014.03.016

Ventura, J., Nuechterlein, K. H., Subotnik, K. L., Gutkind, D., \& Gilbert, E. A. (2000). Symptom dimensions in recent-onset schizophrenia and mania: a principal components analysis of the 24-item Brief Psychiatric Rating Scale. Psychiatry research, 97(2-3), 129-135. https://doi.org/10.1016/S0165-1781(00)00228-6

Viechtbauer, W. (2010). Conducting meta-analyses in R with the metafor package. Journal of Statistical Software, 36(3), 1-48. 
https://doi.org/10.18637/jss.v036.i03

Wampold, B. E. (2001). Contextualizing psychotherapy as a healing practice:

Culture, history, and methods. Applied and Preventive Psychology, 10(2), 69-86. https://doi.org/10.1017/S0962-1849(02)01001-6

*White, R., Gumley, A., McTaggart, J., Rattrie, L., McConville, D., Cleare, S., \& Mitchell, G. (2011). A feasibility study of Acceptance and Commitment Therapy for emotional dysfunction following psychosis. Behaviour Research and Therapy, 49(12), 901-907. https://doi.org/10.1016/j.brat.2011.09.003

Wood, L., Burke, E., \& Morrison, A. (2015). Individual cognitive behavioural therapy for psychosis (CBTp): a systematic review of qualitative literature. Behavioural and Cognitive Psychotherapy, 43(3), 285-297.

https://doi.org/10.1017/S1352465813000970

Wykes, T., Huddy, V., Cellard, C., McGurk, S. R., \& Czobor, P. (2011). A meta-analysis of cognitive remediation for schizophrenia: Methodology and effect sizes. American Journal of Psychiatry, 168(5), 472-485. https://doi.org/10.1176/appi.ajp.2010.10060855 Wykes, T., Reeder, C., Landau, S., Everitt, B., Knapp, M., Patel, A., \& Romeo, R. (2007). Cognitive remediation therapy in schizophrenia: randomised controlled trial. The British Journal of Psychiatry, 190(5), 421-427. https://doi.org/10.1192/bjp.bp.106.026575

Zilcha-Mano, S. (2017). Is the alliance really therapeutic? Revisiting this question in light of recent methodological advances. American Psychologist, 72(4), 31.

https://doi.org/10.1037/a0040435 


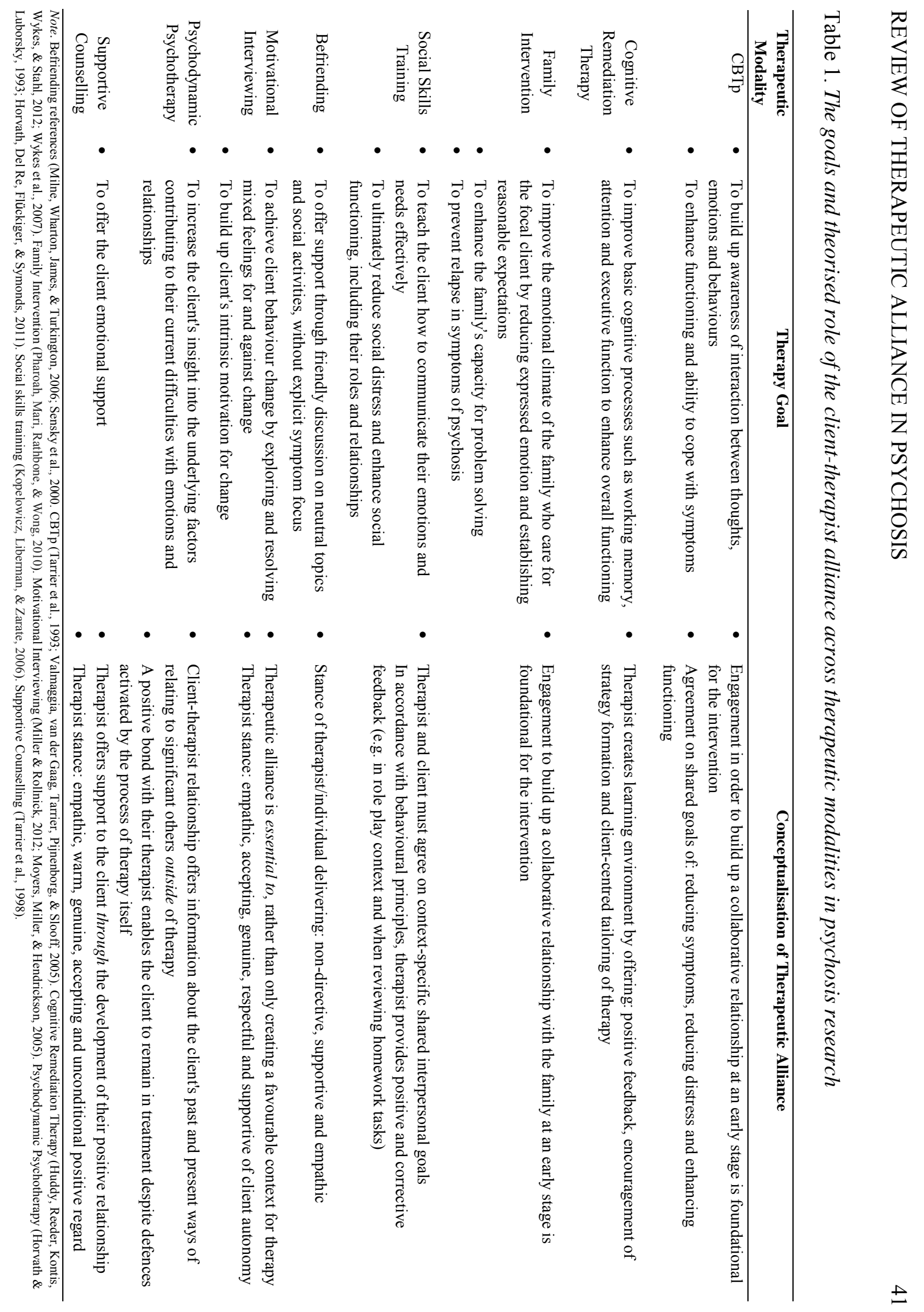




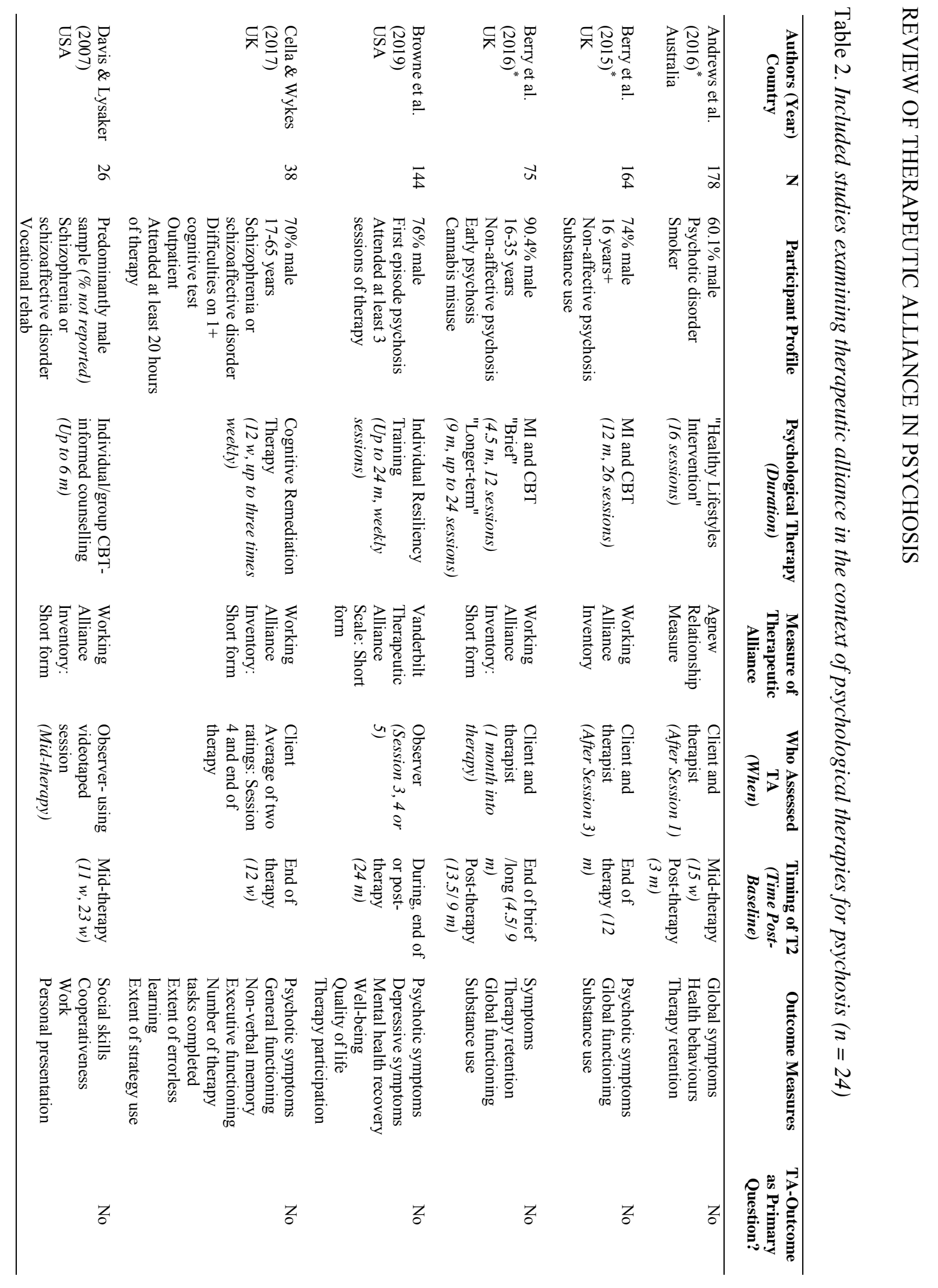




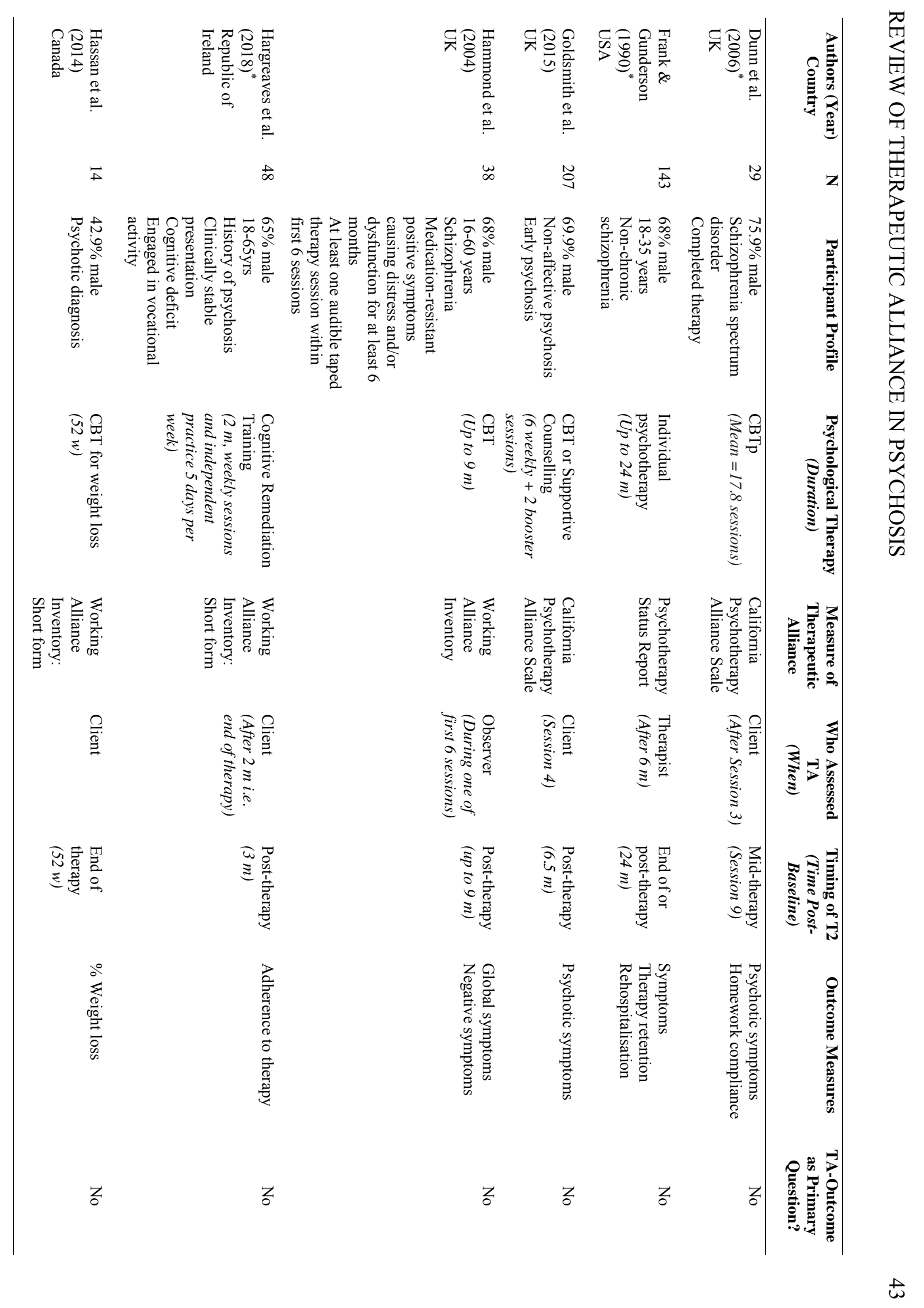




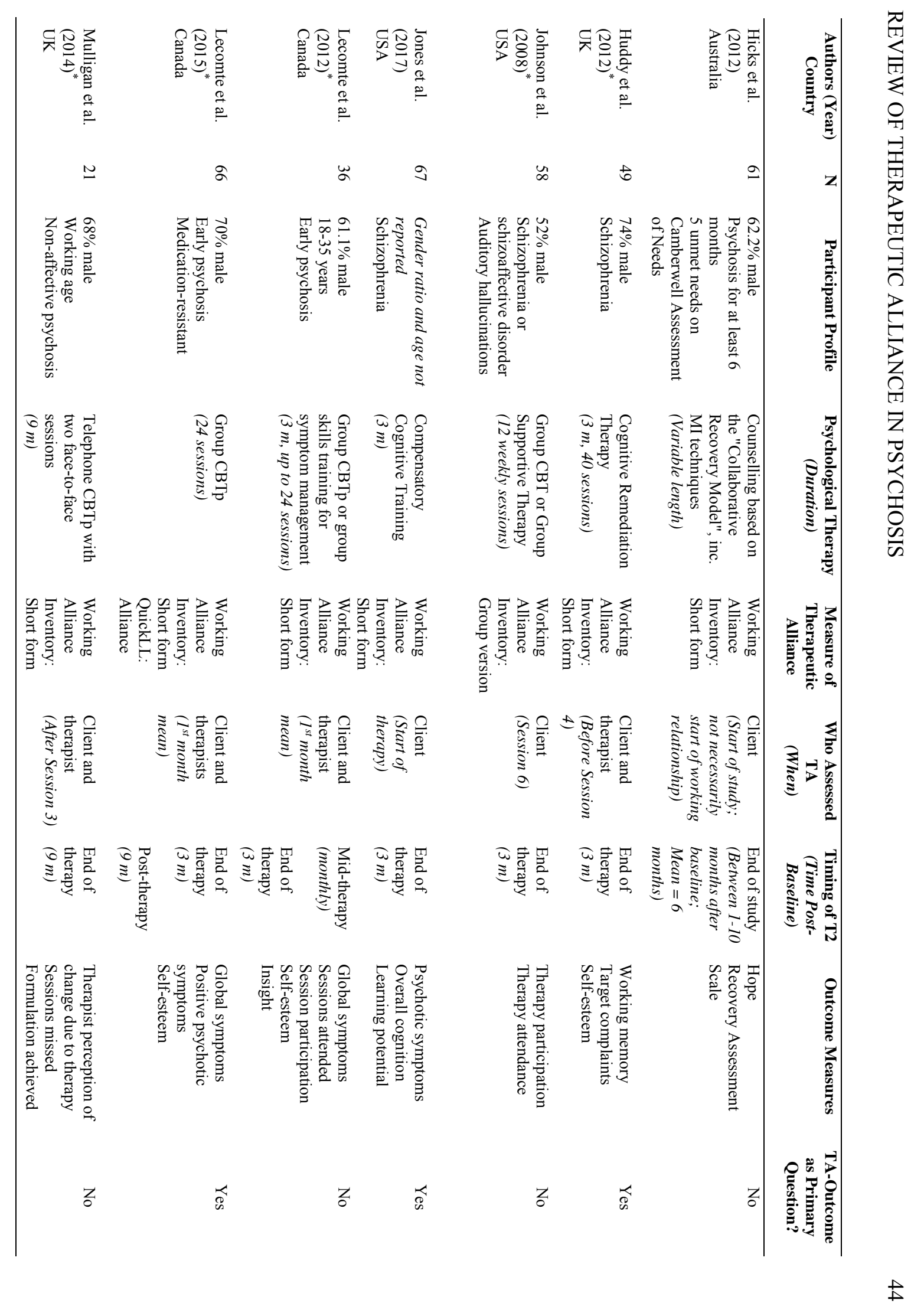




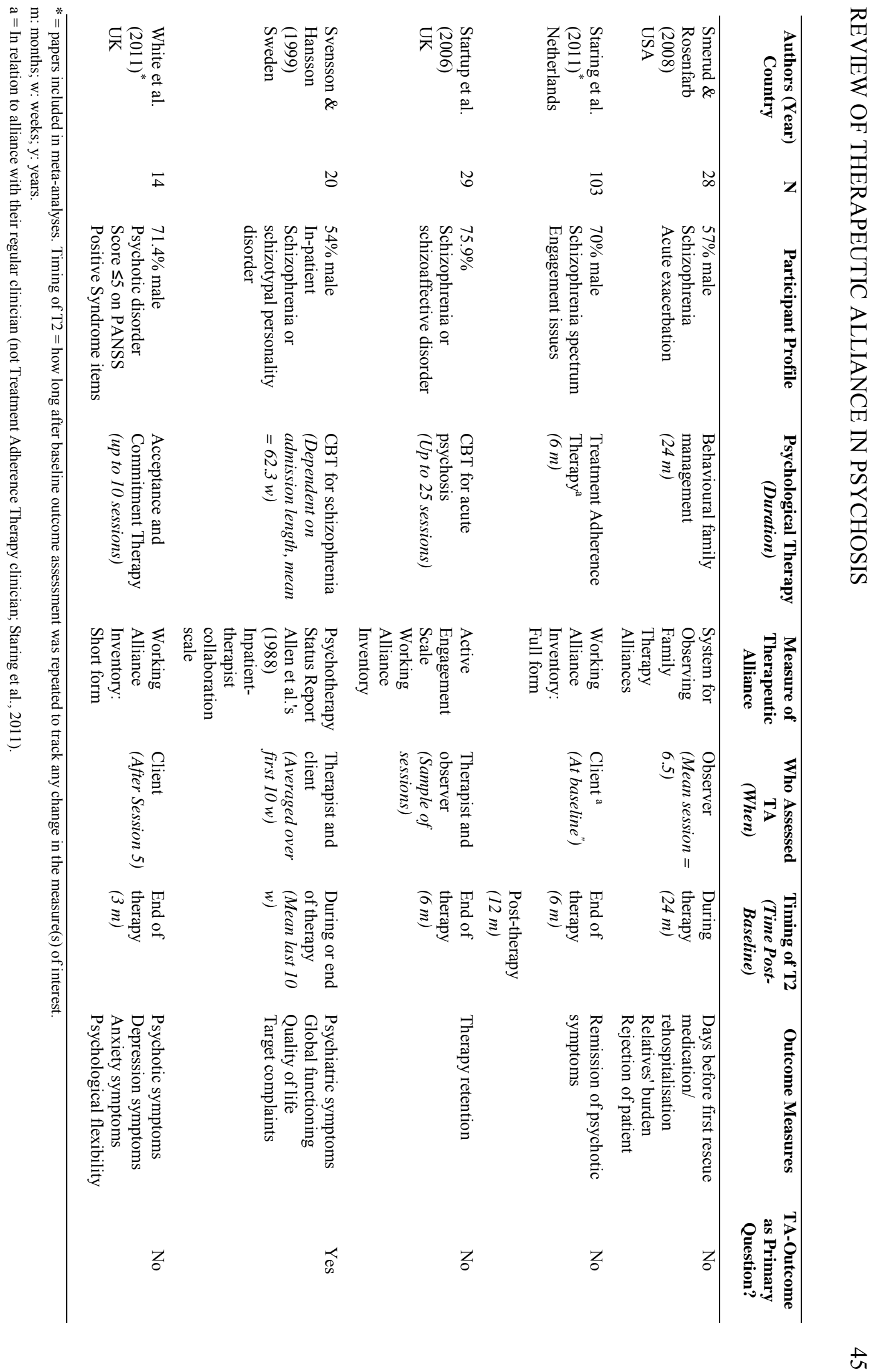




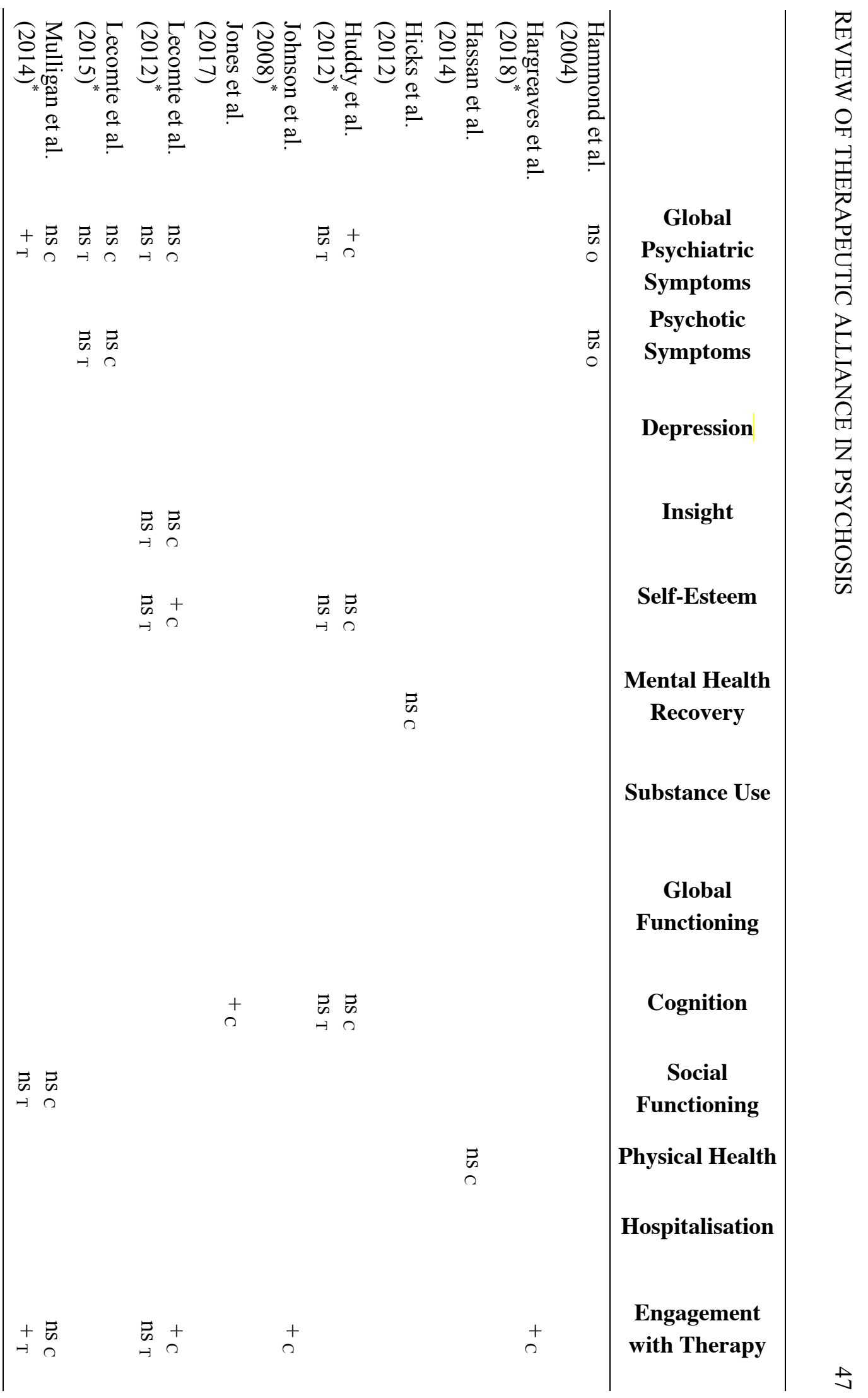




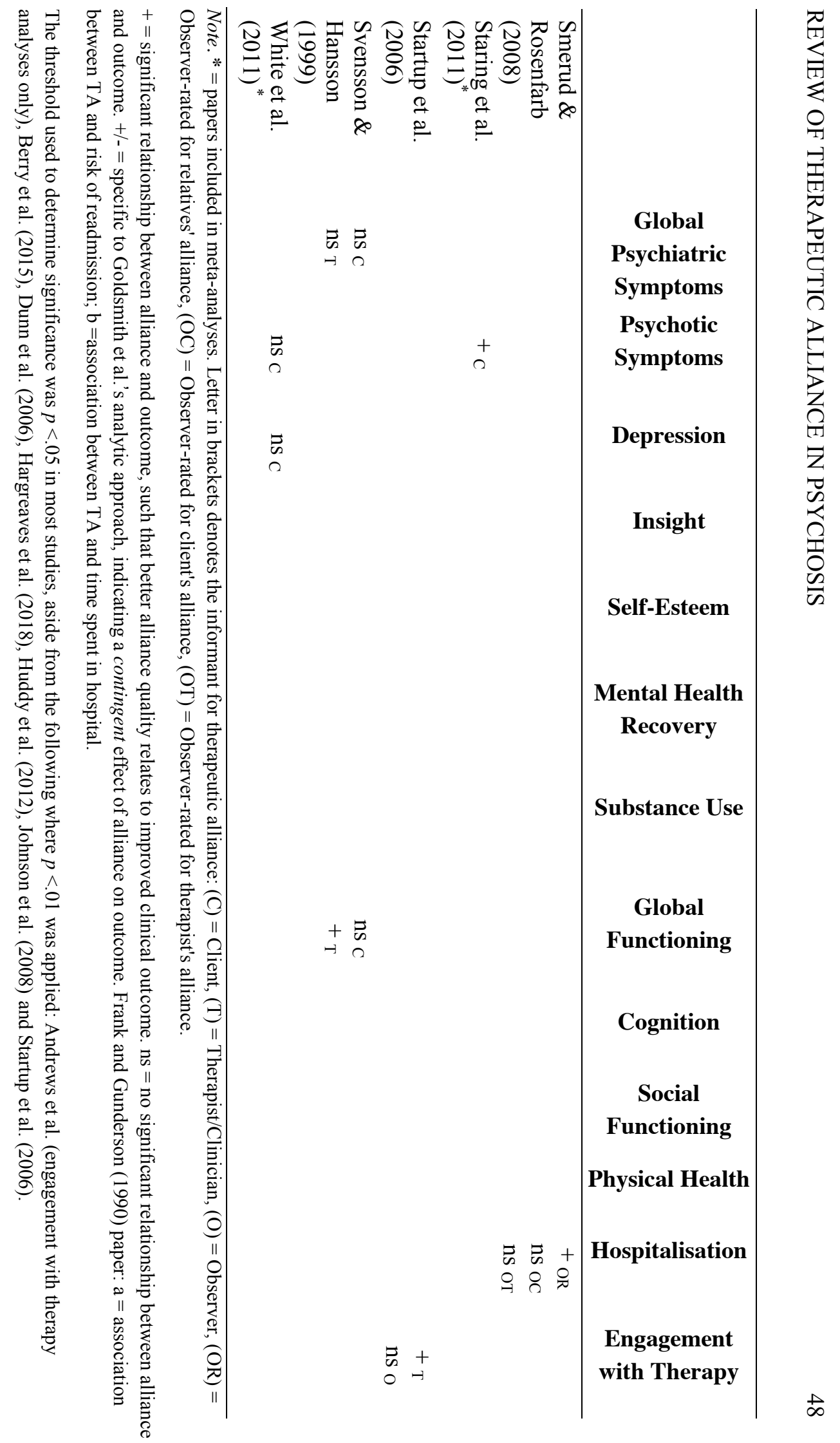


Figure 1. PRISMA flow-chart of article selection process

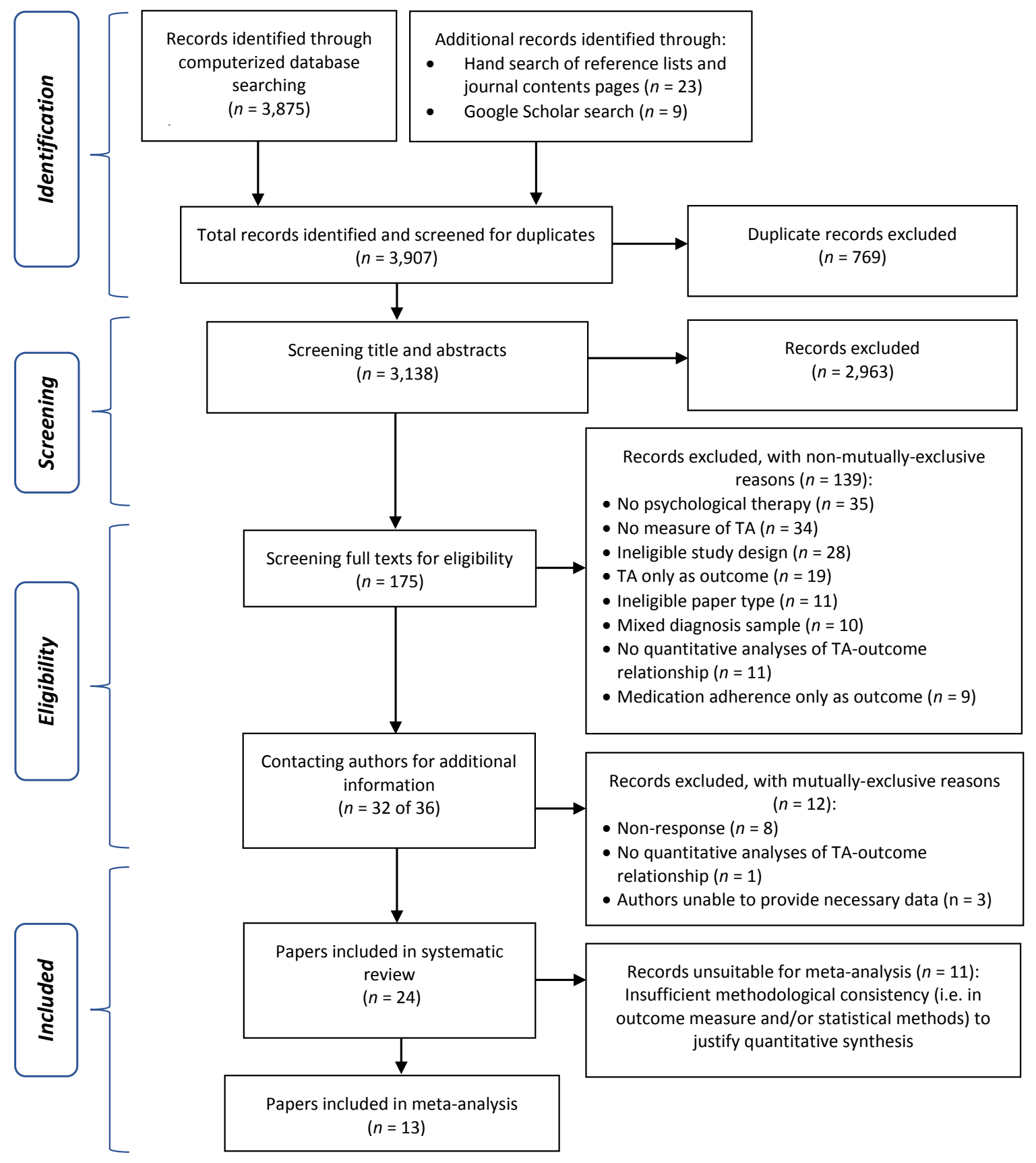




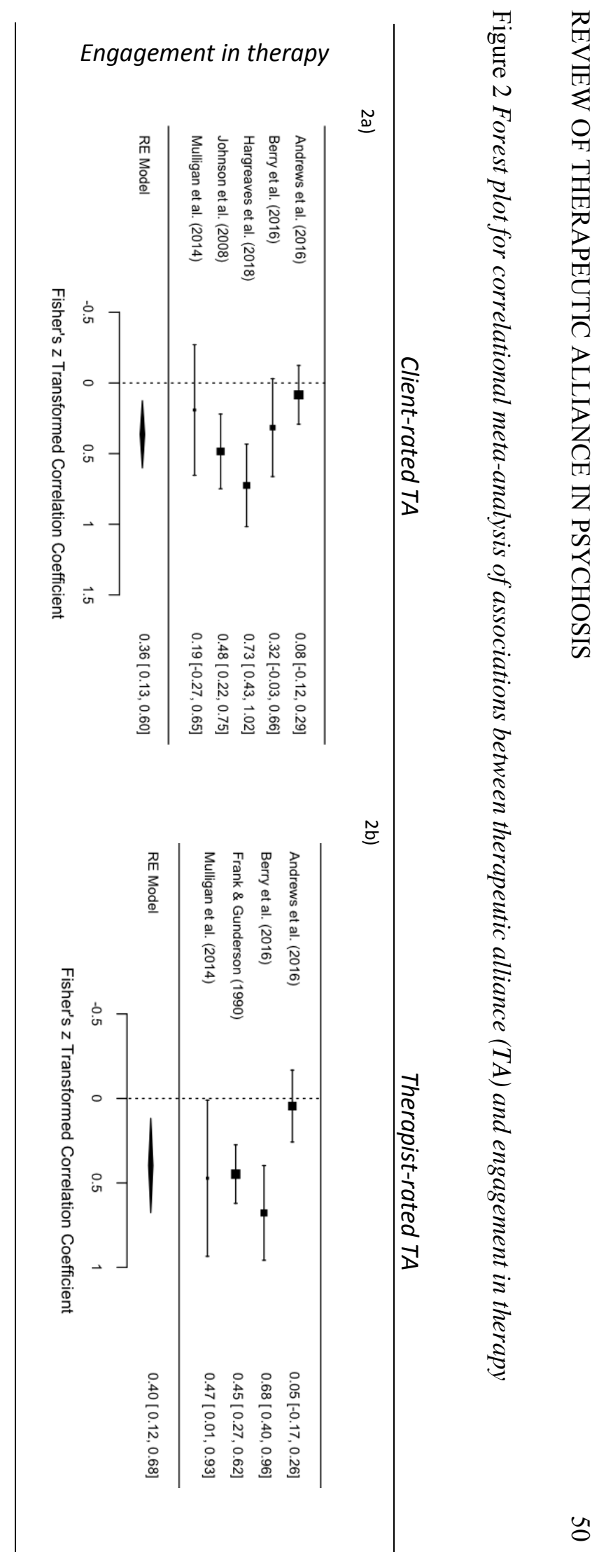




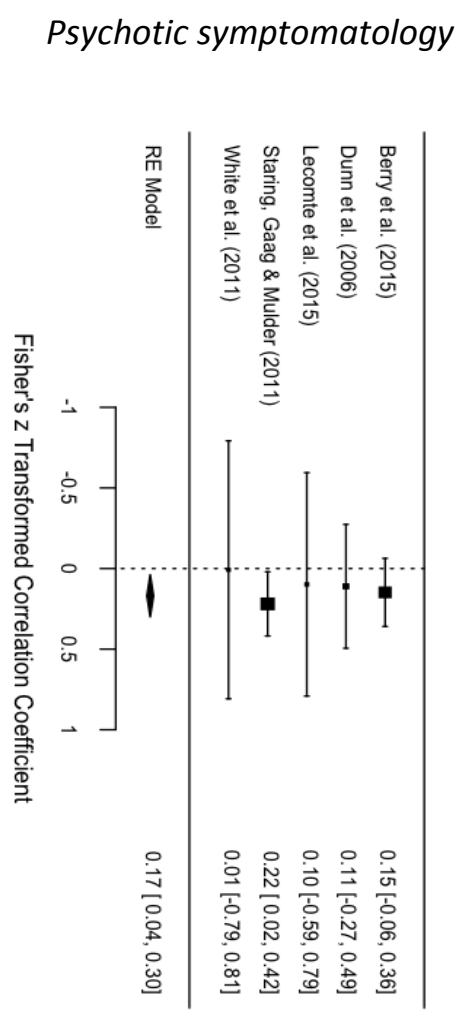

$\stackrel{w}{\Omega}$

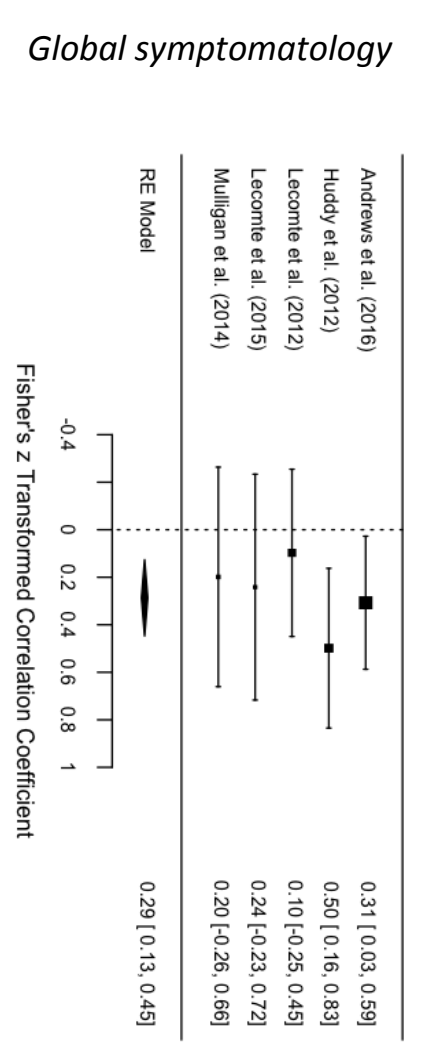

$\stackrel{w}{\mathscr{\omega}}$
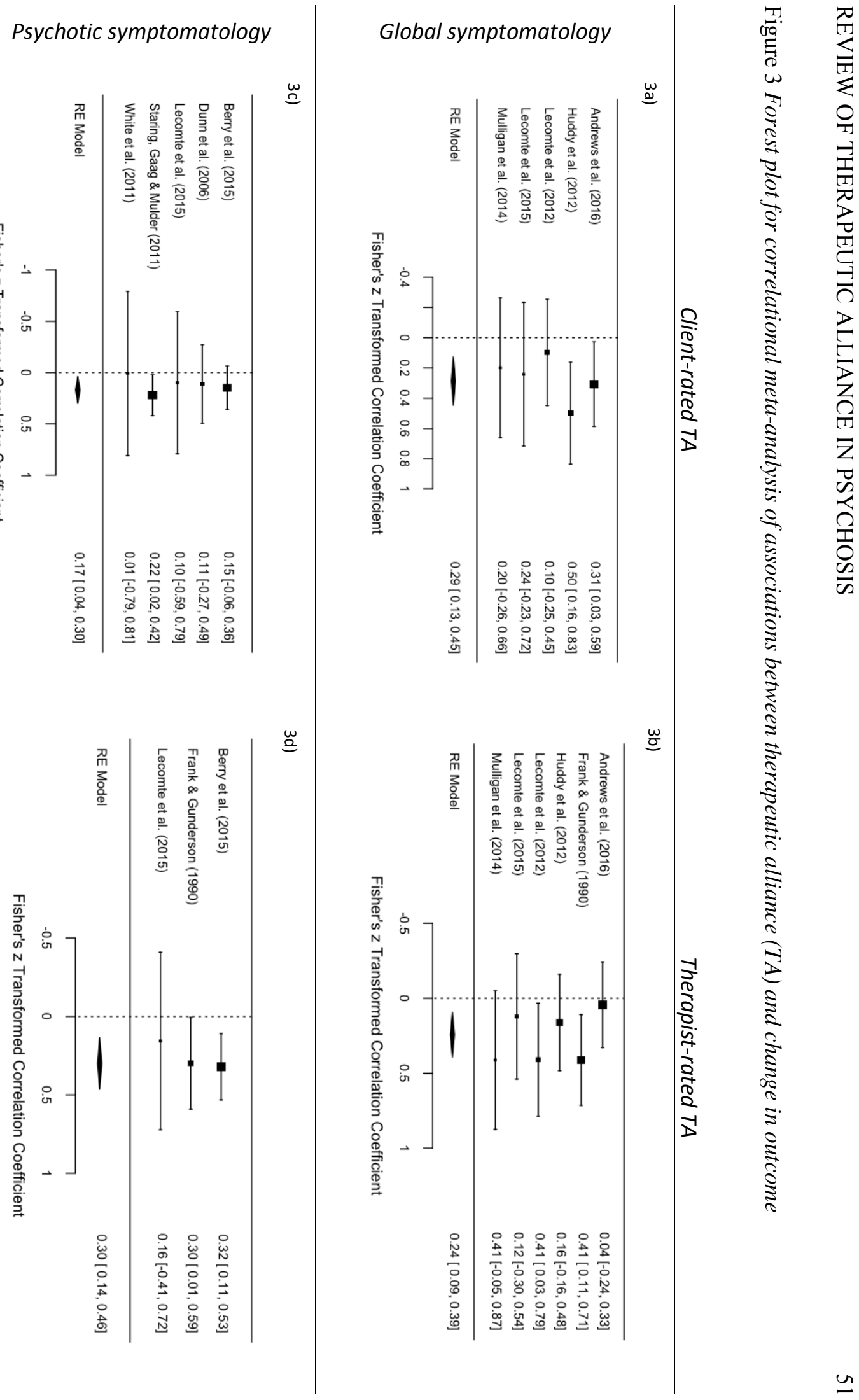


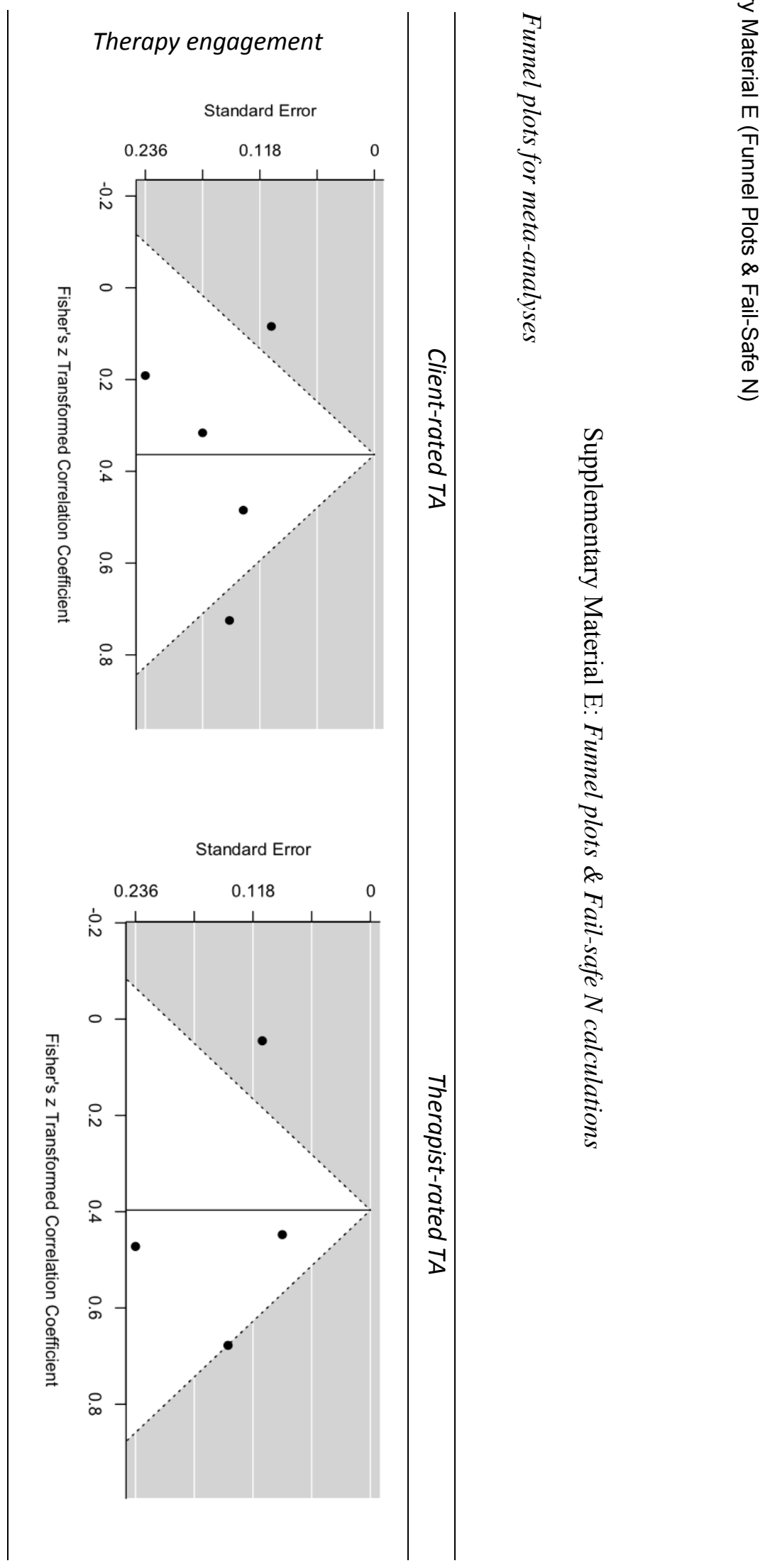


Change in psychotic symptomatology
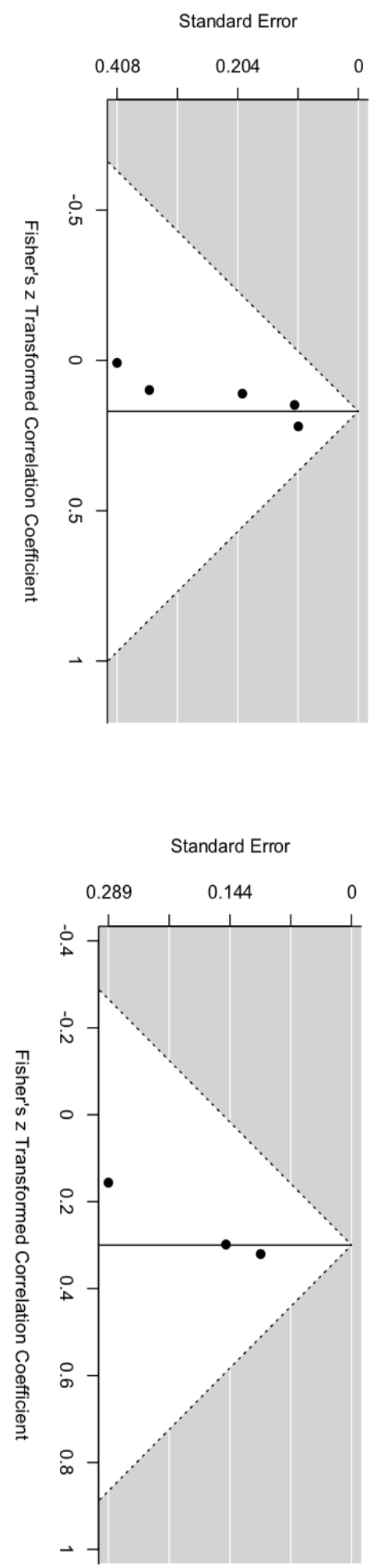

Change in global symptomatology

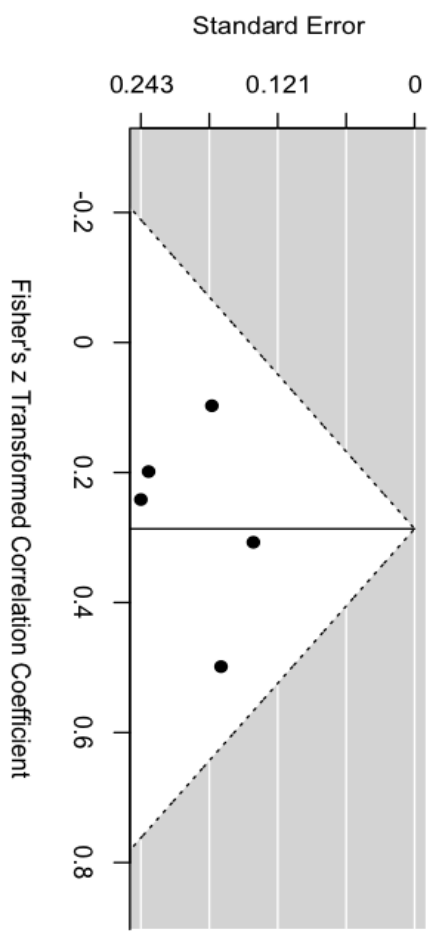

$\stackrel{2}{0}$
$\frac{1}{7}$
$\frac{1}{2}$
$\frac{1}{0}$
$\frac{1}{D}$
-7

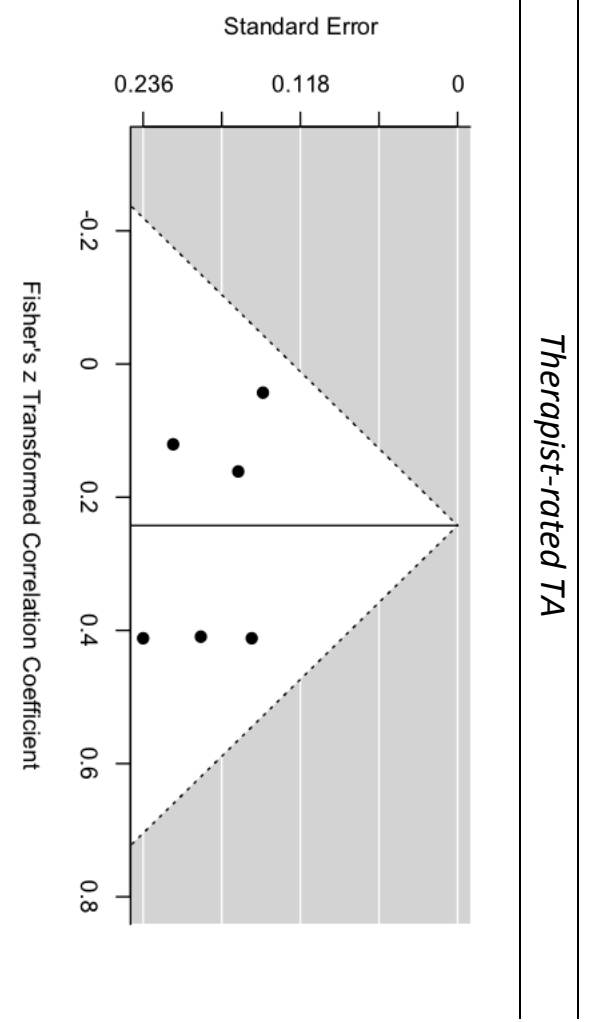




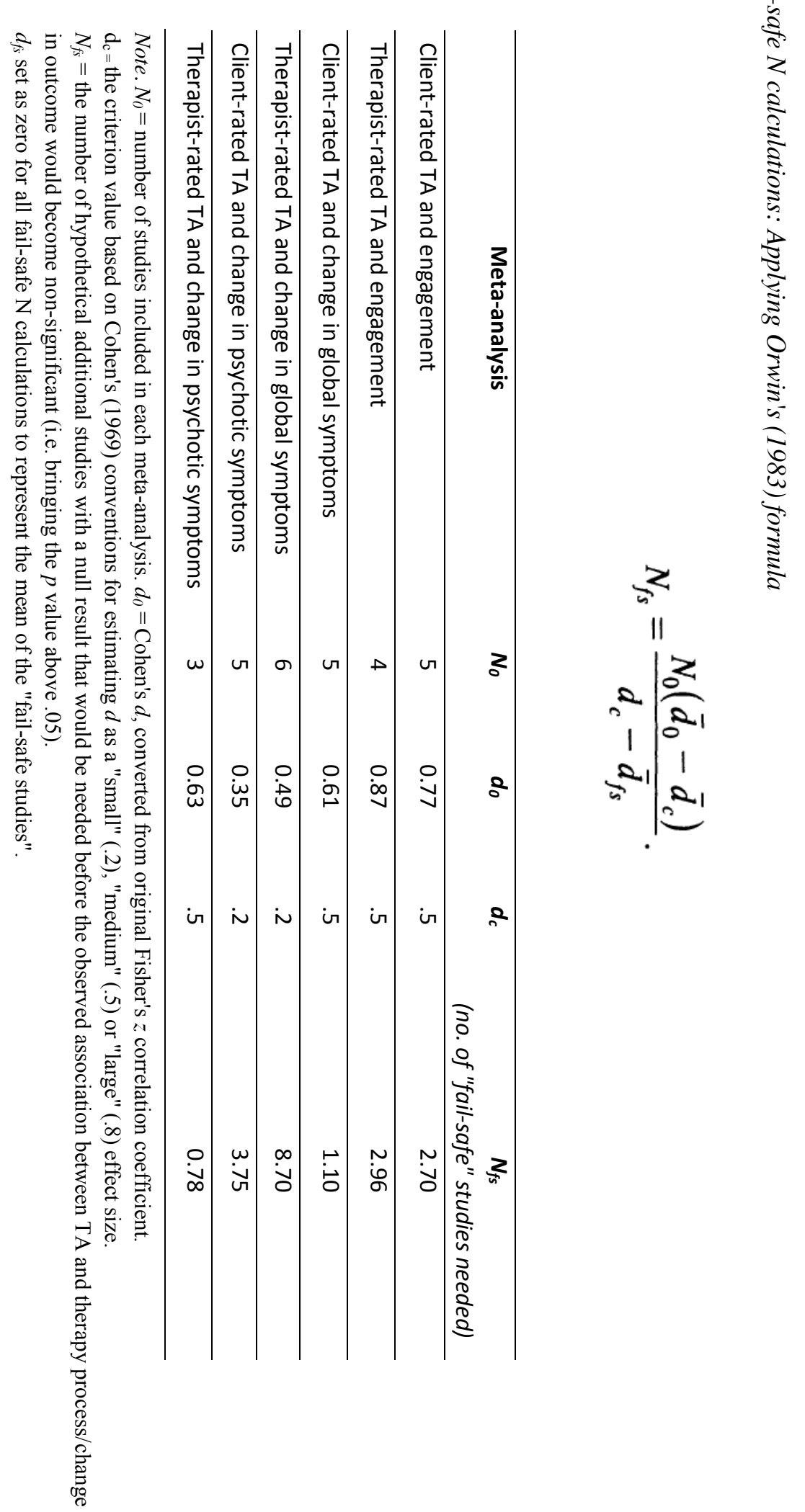


Supplementary Material F: Sensitivity analysis for correlational meta-analysis of therapistrated TA and engagement in therapy

Forest plot without Andrews et al. paper

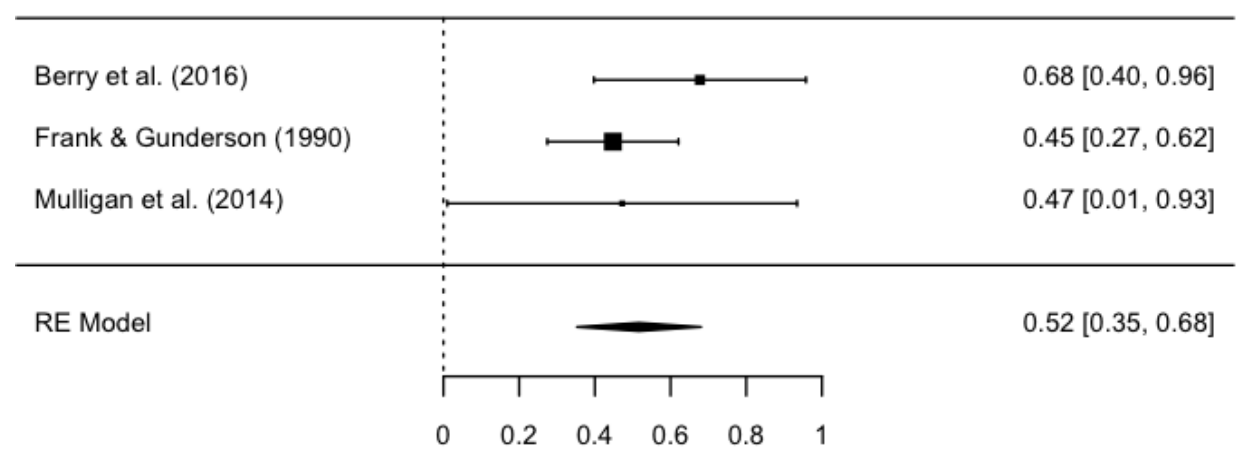

Fisher's z Transformed Correlation Coefficient

Funnel plot without Andrews et al.paper

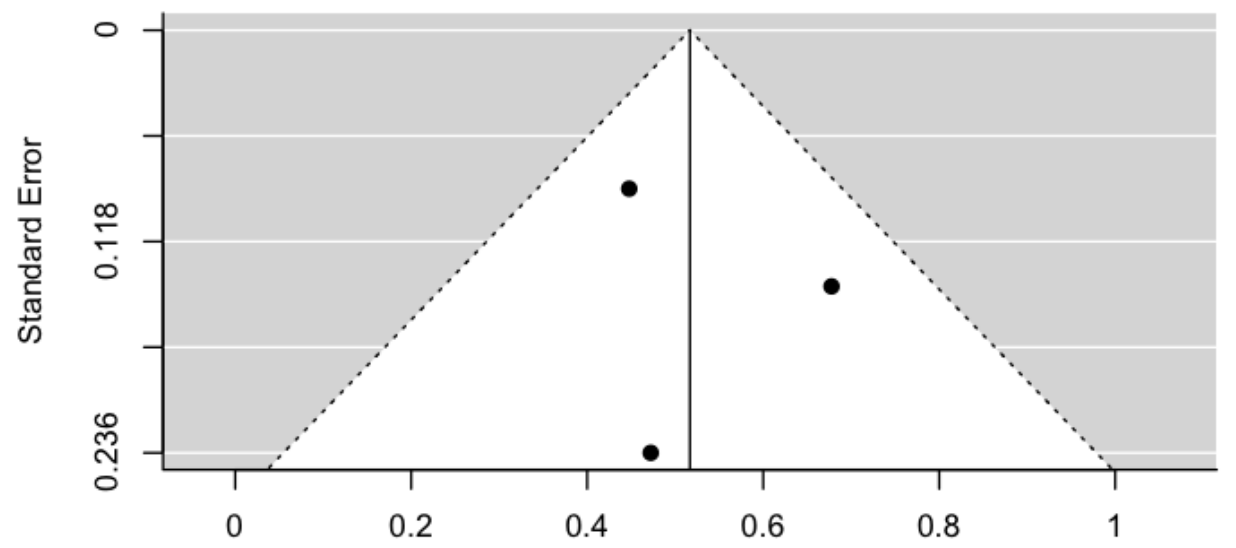

Fisher's z Transformed Correlation Coefficient 
Supplementary Material A: Search terms

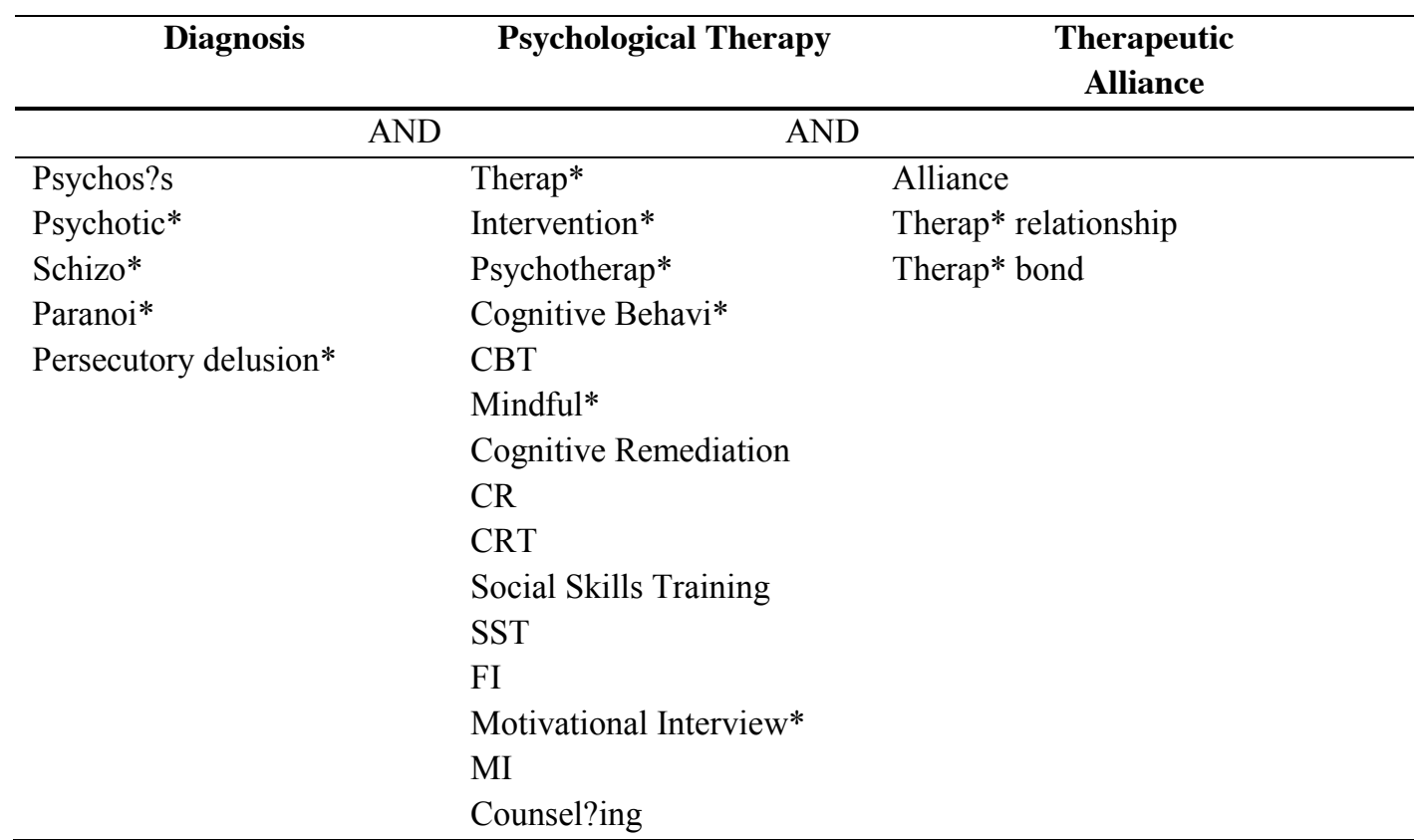

Note. Searches were also tested with an additional column for 'Treatment Outcome', however, as criterion iv) aimed to capture a range of definitions of treatment outcome, it was felt that this additional search component would risk excessive specificity. 
Supplementary Material B: Adapted NIH quality assessment tool for before-after (pre-post)

studies with no control group

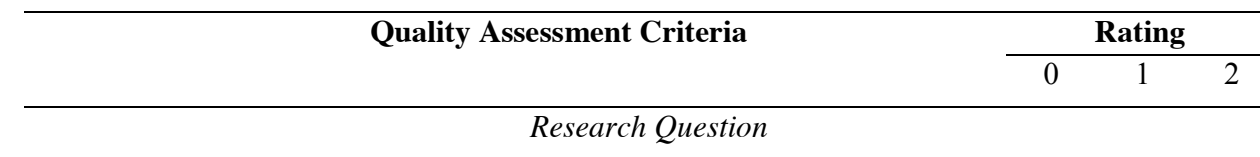

1. Was the study question/objective clearly stated?

\begin{tabular}{ll}
\hline & \multicolumn{1}{c}{ Sample } \\
\hline $2 . \quad$ Were eligibility/selection criteria for the study population pre- \\
specified and clearly described?
\end{tabular}

3. Were the participants in the study representative of those who would be eligible for the test/service/intervention in the general or clinical population of interest?

AND

Were all participants who met the prespecified entry criteria enrolled?

4. Was the sample size sufficiently large to provide confidence in the findings?

AND

Was a sample size calculation reported?

5. Was the loss at T2 assessment (after baseline) $20 \%$ or less?

$\overline{\text { Intervention }}$

6. Was the test/service/intervention clearly described and delivered consistently across the study population?

7. Was the test/service/intervention delivered as described and with consistency across the study population?

\begin{tabular}{|c|c|}
\hline \multicolumn{2}{|r|}{ Quality of Measures } \\
\hline 8. & $\begin{array}{l}\text { Were the people assessing the outcomes blinded to the participants' } \\
\text { exposures/interventions? }\end{array}$ \\
\hline 9. & $\begin{array}{l}\text { Were the measures prespecified, clearly defined, valid, reliable and } \\
\text { assessed consistently across all study participants? }\end{array}$ \\
\hline & Statistical Analyses \& Reporting \\
\hline 10. & $\begin{array}{l}\text { Did the statistical methods examine changes in outcome measures } \\
\text { from before to after the intervention? } \\
\text { AND } \\
\text { Were those lost to at } \mathrm{T} 2 \text { accounted for in the analysis? }\end{array}$ \\
\hline 11. & $\begin{array}{l}\text { Did reporting of the statistical tests provide } \mathrm{p} \text { values for the pre- to- } \\
\text { post changes? } \\
\text { AND } \\
\text { Were the findings reported clearly, regardless of whether they were } \\
\text { significant or non-significant? }^{+}\end{array}$ \\
\hline
\end{tabular}




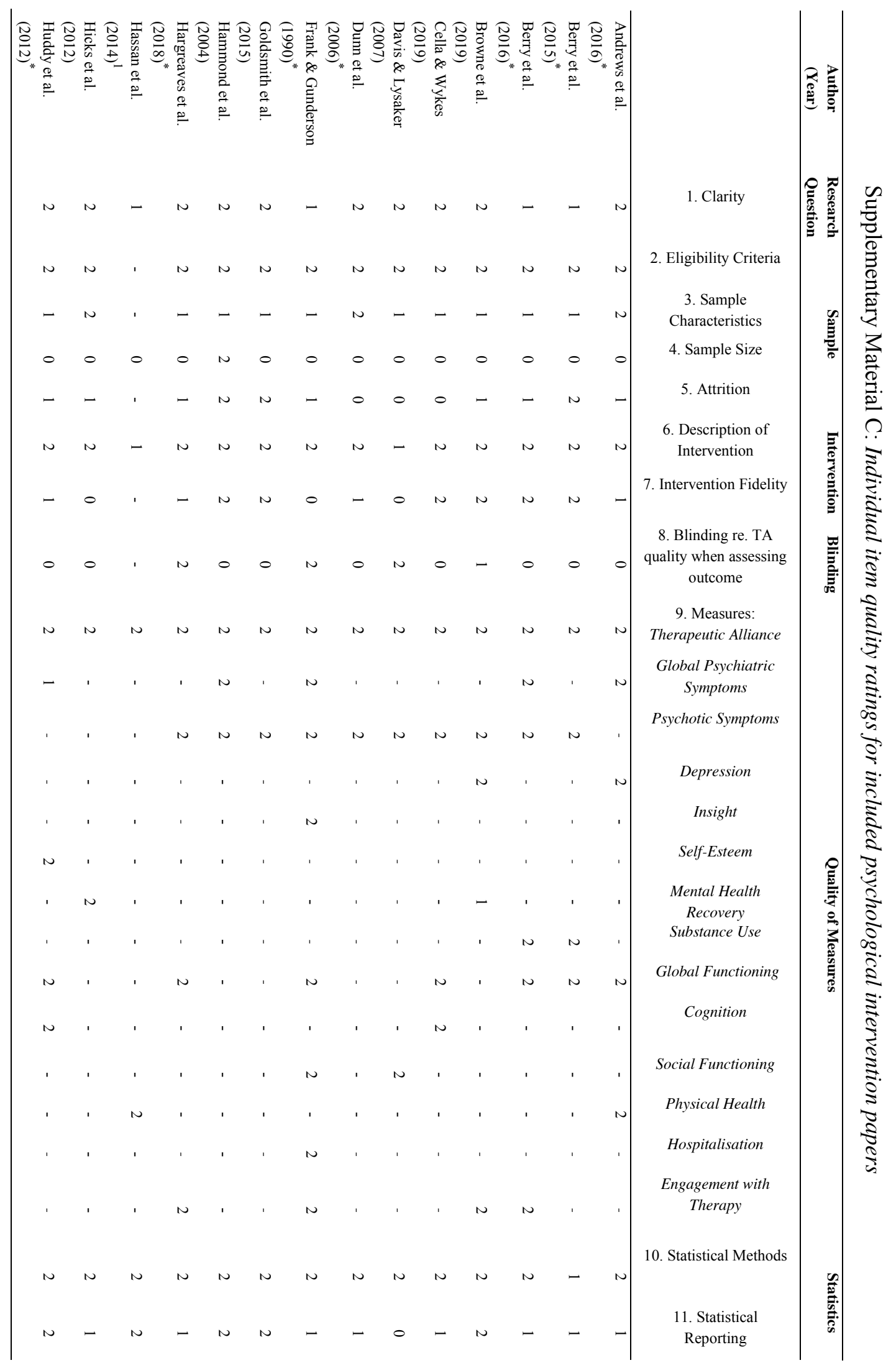




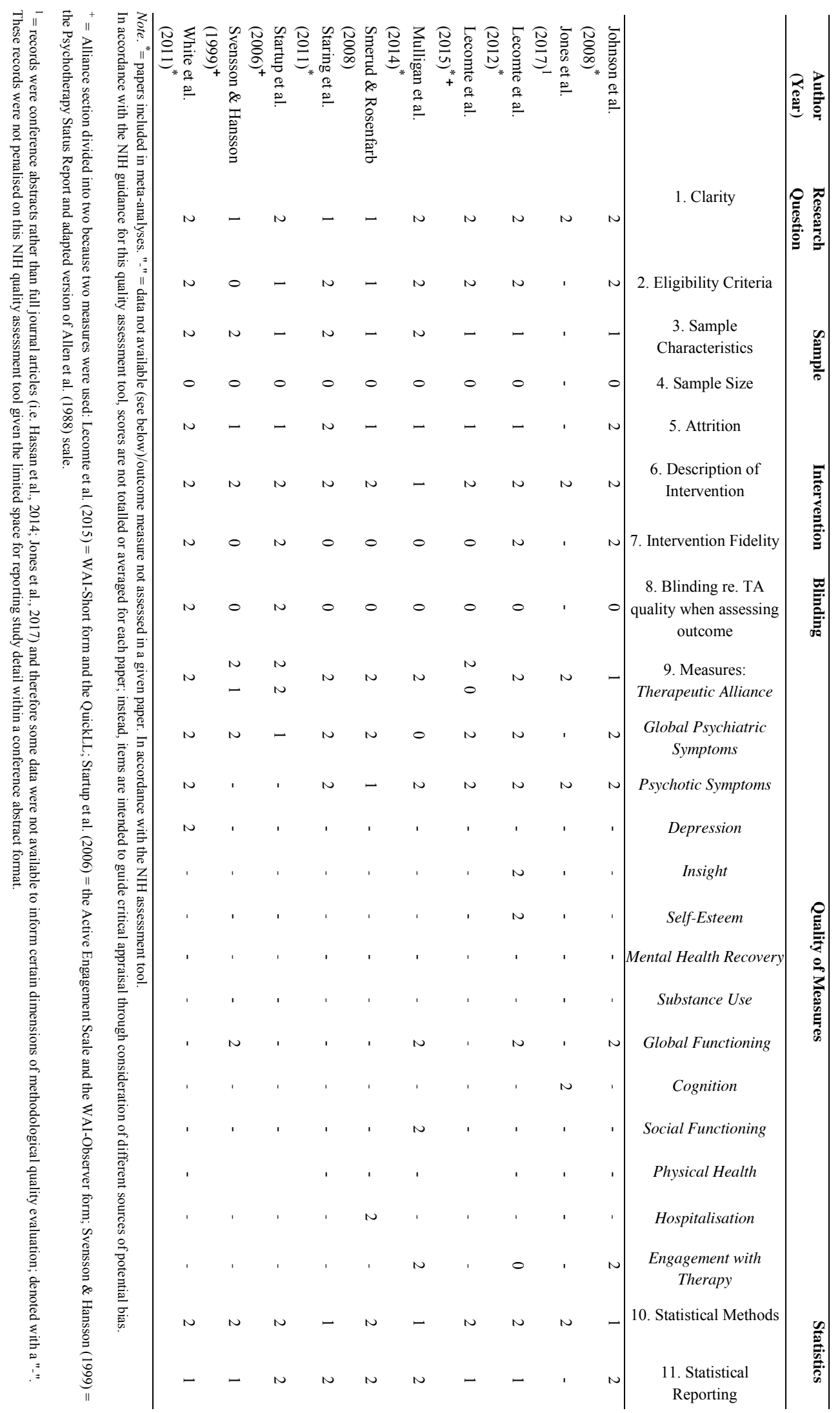




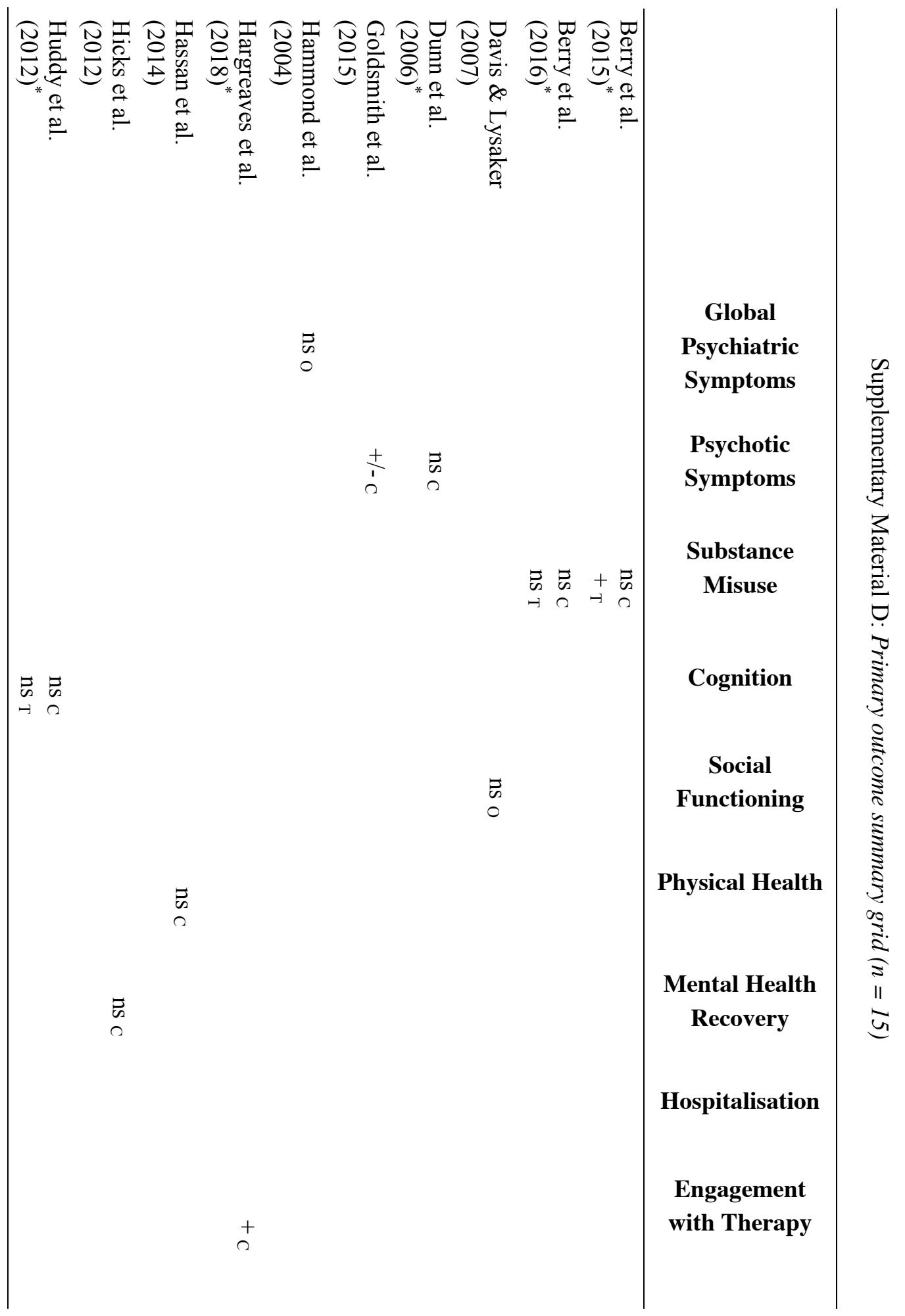




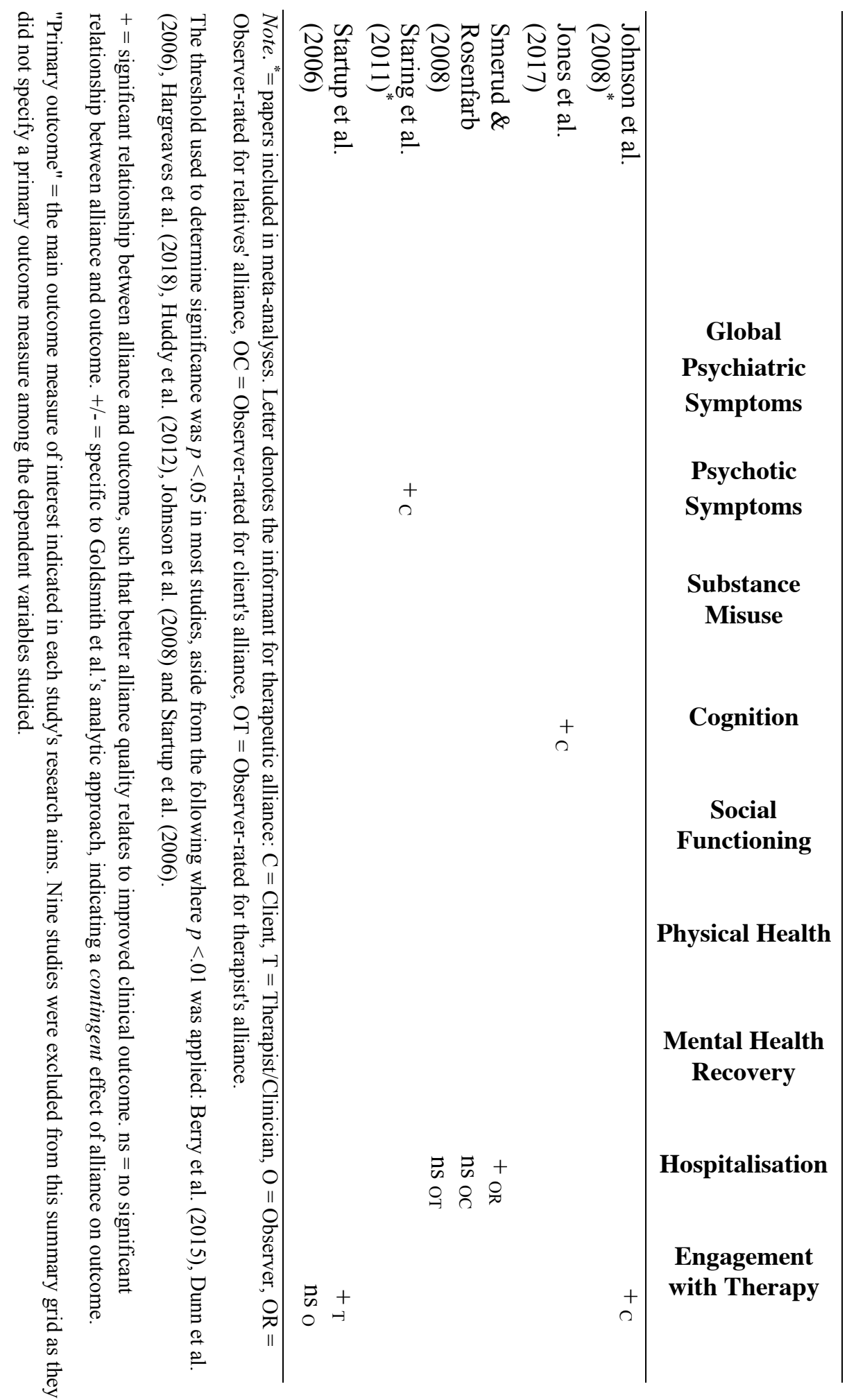

